\title{
Longitudinal Emittance Measurements in the Booster and AGS during the 2014 RHIC Gold Run
}

\author{
K. Zeno
}

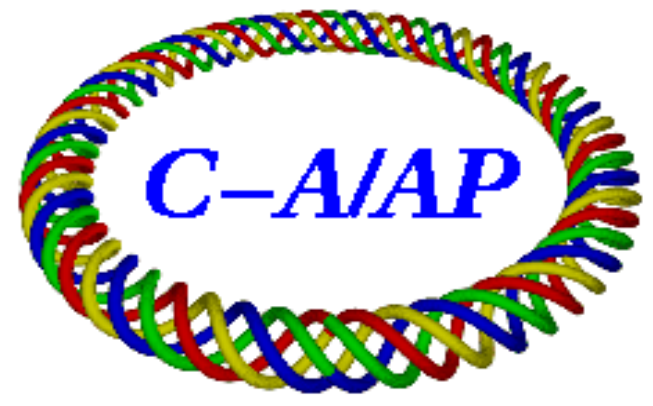

\section{Collider-Accelerator Department Brookhaven National Laboratory \\ Upton, NY 11973}

Notice: This document has been authorized by employees of Brookhaven Science Associates, LLC under Contract No. DE-AC02-98CH10886 with the U.S. Department of Energy. The United States Government retains a nonexclusive, paid-up, irrevocable, world-wide license to publish or reproduce the published form of this document, or allow others to do so, for United States Government purposes. 


\section{Longitudinal Emittance Measurements in the Booster and AGS during the 2014 RHIC Gold Run}

Keith Zeno

$8 / 18 / 2014$ 
This note describes longitudinal emittance measurements that were made in the Booster and AGS during the 2014 RHIC Gold run. It also contains an overview of the longitudinal aspects of their setup during this run.

Each bunch intended for RHIC is composed of beam from 4 Booster cycles, and there are 2 of them per AGS cycle. For each of the 8 Booster cycles required to produce the 2 bunches in the AGS, a beam pulse from EBIS is injected into the Booster and captured in four $\mathrm{h}=4$ buckets. Then those bunches are accelerated to a porch where they are merged into 2 bunches and then into 1 bunch (see figure 1). That bunch is accelerated and extracted; it then passes through a foil in BtA where it is stripped from charge state +32 to +77 . Then it is injected into an AGS h=16 bucket. As shown in figure 2 , at the end of the AGS injection process there are 2 evenly spaced groups of 4 bunches from the 8 Booster cycles corresponding to a bunch pattern of $\{1,1,1,1,0,0,0,0,1,1,1,1,0,0,0,0\}^{1}$. Each group of 4 bunches is then merged into 2 bunches in $h=8$ buckets, $\{1,1,0,0,1,1,0,0\}$. Each group of 2 bunches is then merged into 1 bunch in $h=4$ buckets, $\{1,0,1,0\}$. With the help of a "bunch squeeze", that uses the $h=8$ and $h=4$ cavities, these 2 bunches are then put into two $h=12$ buckets, $\{1,0,0,0,0,0,1,0,0,0,0,0\}$, and accelerated to extraction (see figure 3).

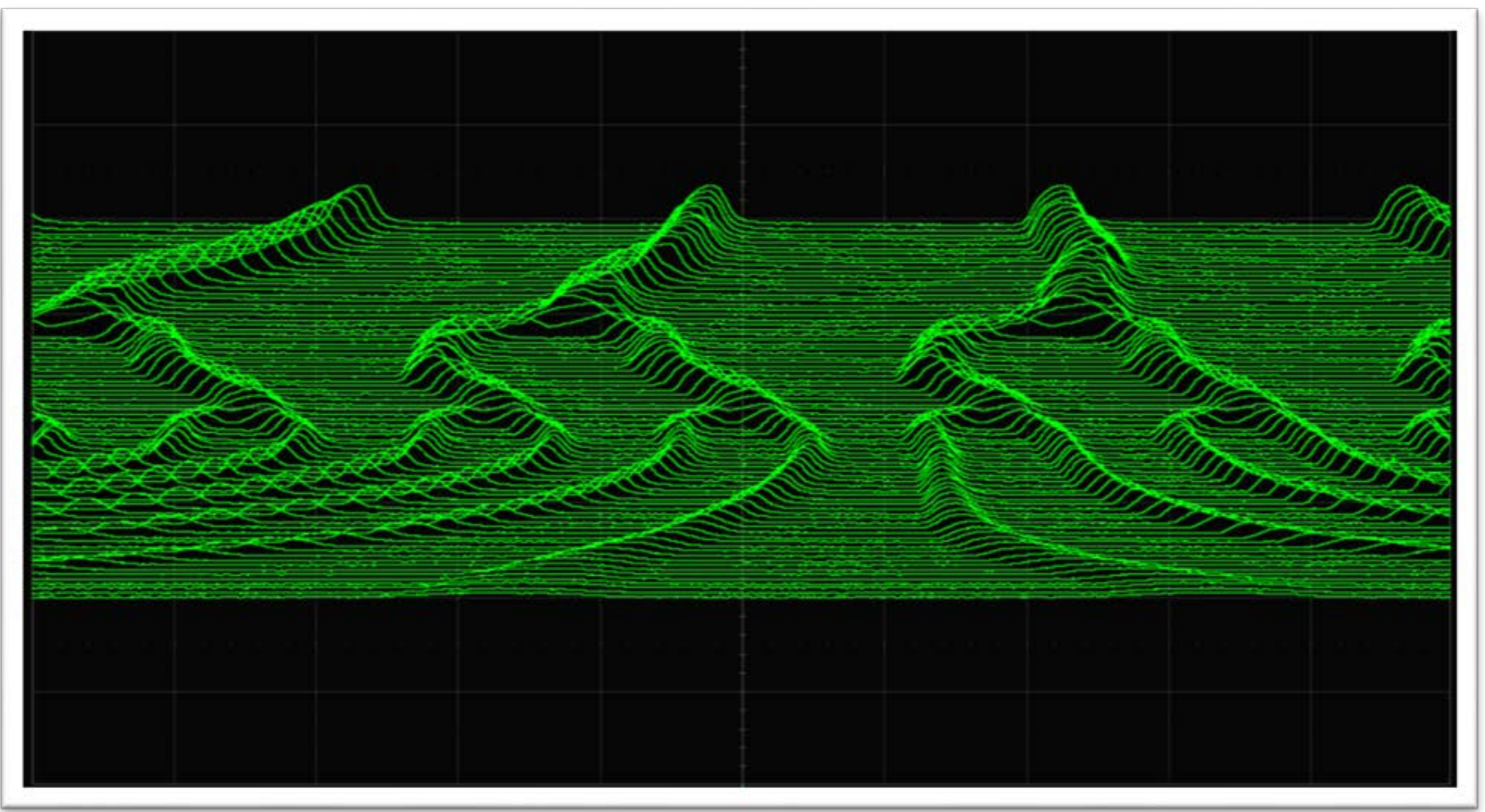

Figure 1 : A mountain range display of the Booster wall current monitor from injection to late acceleration showing capture, early acceleration, the 4 to 2 and 2 to 1 merges, and further acceleration. ${ }^{2}$

This bunch squeeze is used to make the 2 bunches narrower so that they will each fit into an $\mathrm{h}=12$ bucket. Despite these efforts though some beam falls outside of the 2 main $\mathrm{h}=12$ buckets and winds up in the other $\mathrm{h}=12$ buckets. These satellite bunches are known as "baby bunches". They aren't visible in

\footnotetext{
${ }^{1}$ Where 1 indicates a full bucket and 0 an empty bucket.

Jun 2520141350 elog entry
} 
figure 3 because they are quite small, normally comprised of 2-3\% of the total beam. Figure 4 has the wall current monitor gain raised high enough so that they are visible.

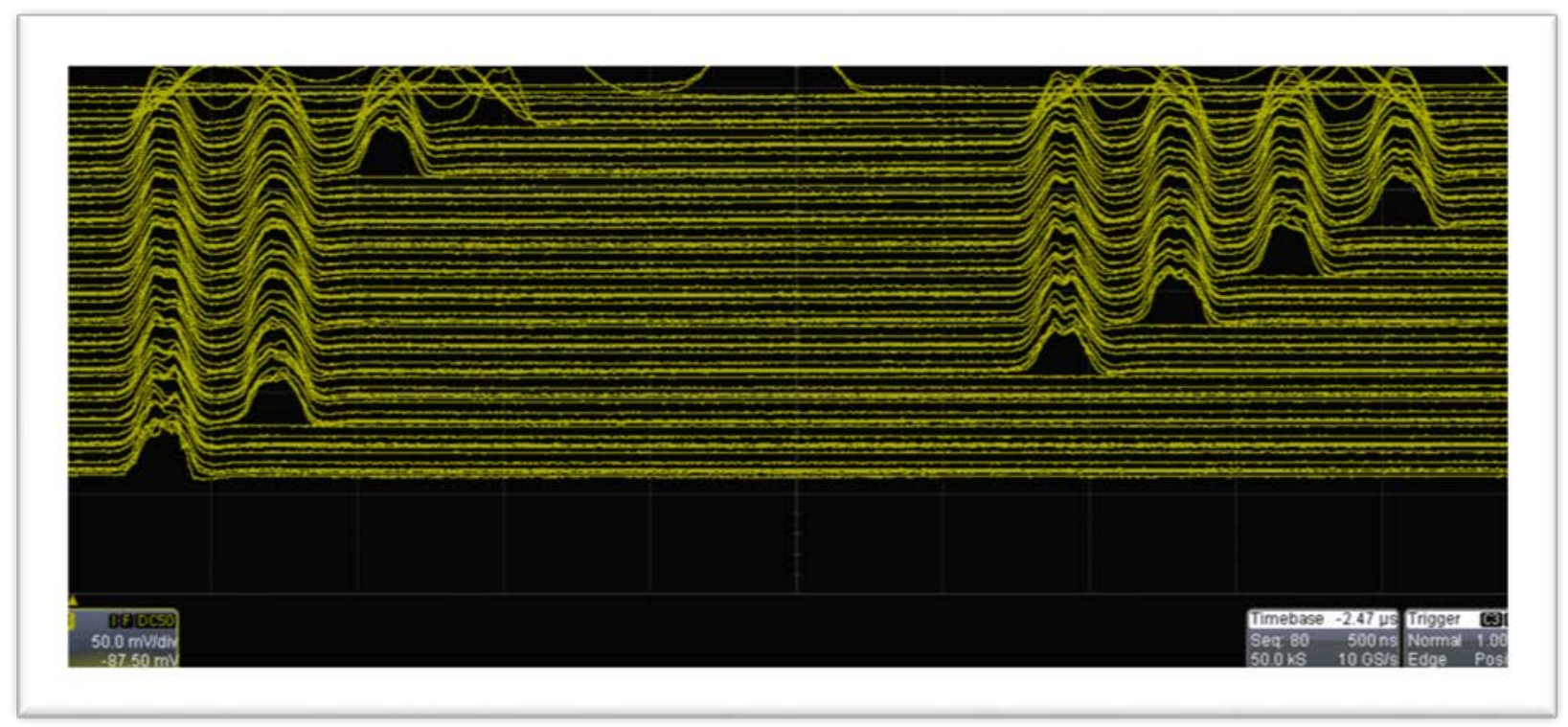

Figure 2: A mountain range display showing the injection and cogging of the 8 bunches on the AGS injection porch before merging. The time between consecutive injections is $\mathbf{2 0 0} \mathrm{ms}$. Note that the entire span of 16 buckets isn't shown here. If the bunch on the far left is in bucket 1 then the order in which the buckets are filled is $\{1,2,7,8,-,-,-,-, 3,4,5,6,-,-,-,-\}$. This was the cogging pattern for most of the run. ${ }^{3}$

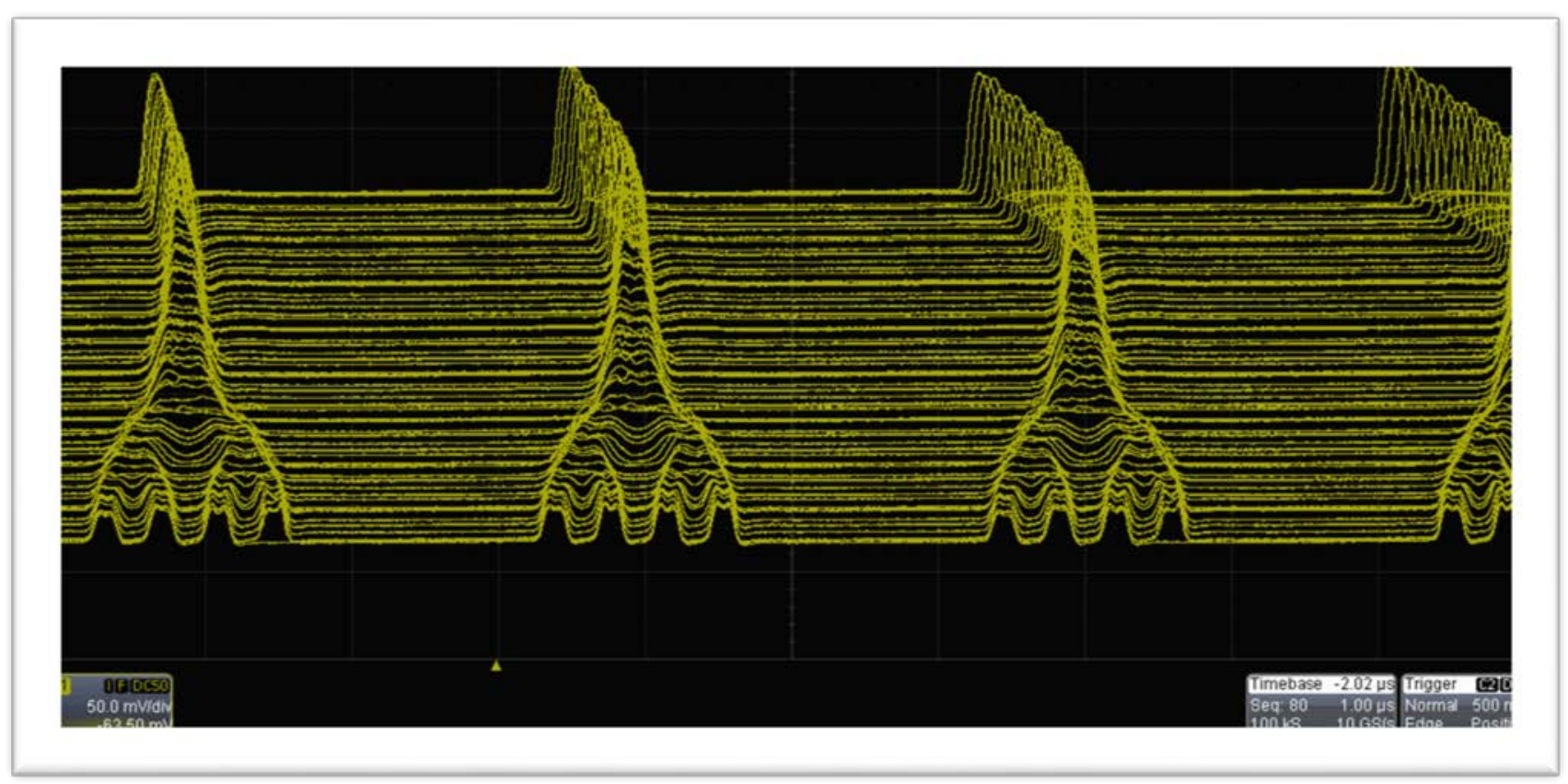

Figure 3: Mountain range display of AGS 4->2 and 2->1 merges, bunch squeeze, and $\mathrm{h}=12$ acceleration. ${ }^{4}$

\footnotetext{
${ }^{3}$ May 920141518 elog entry

${ }^{4}$ Mar 62014 elog entry
} 


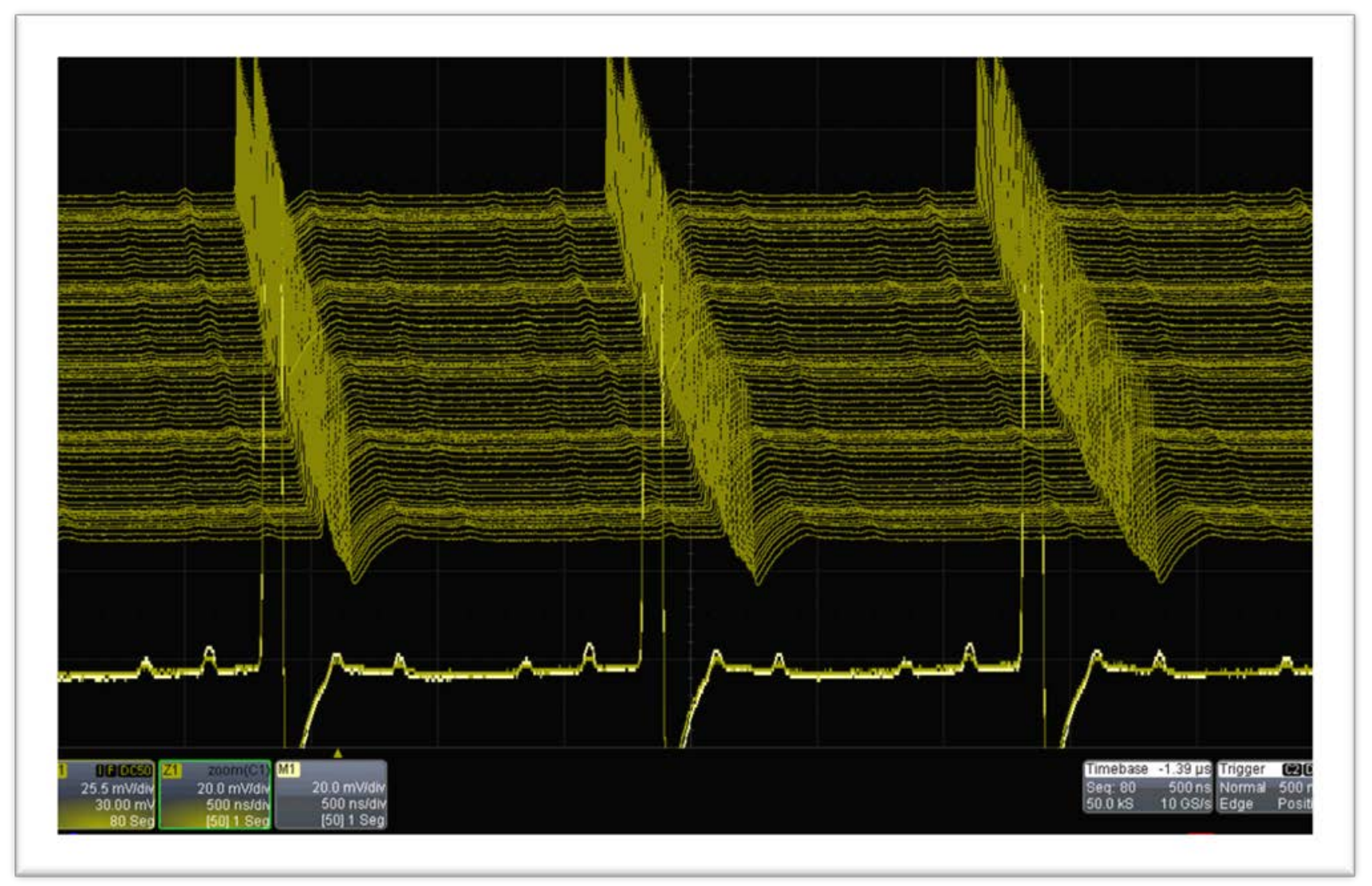

Figure 4: An AGS Mountain range display during the $h=12$ part of the cycle with the gain of the wall current monitor signal raised so that the baby bunches are visible. The 2 traces at the very bottom are just the bottom trace of the mountain range part of the figure and a saved trace of same taken under slightly different conditions and overlaid. ${ }^{5}$

\section{Constraints on the Booster Magnet Cycle}

In order to provide enough intensity for RHIC, it is necessary to use 8 loads of beam from EBIS, which requires 9 Booster cycles, 8 with beam, and one "dummy" cycle. The AGS L10 cavity which provides the $\mathrm{h}=4$ part of the merge has a relatively small frequency range which constrains the Booster extraction energy. ${ }^{6}$ Also, if the extraction energy is lowered the BtA stripping efficiency goes down, the effect of the foil on momentum spread increases, and generally the transfer efficiently deteriorates. The Booster cycle length is constrained to increments of $1 / 60^{\text {th }}$ of a second. Increasing the Booster cycle length to more than 200 ms causes harmonics in the power line voltage that are prohibited by the power company. An intermediate porch is required for a $200 \mathrm{~ms}$ cycle to keep these harmonics under their limits. Serendipitously, the requirements for this porch allow for the 2 bunch merges to take place there. Limitations imposed by the Booster Main Magnet power supply itself and maximum RF voltage prevent a shorter cycle with the same extraction energy from being used. Extraction occurs at the peak of the magnet cycle, and injection occurs at $10.5 \mathrm{~ms}$ after the beginning of the cycle (Bt0). The maximum

\footnotetext{
${ }^{5}$ Mar 192014 elog entry

6 Potentially there are ways of getting around this constraint such as accelerating after injection up to the energy required for the merge, but they complicate matters as well.
} 
main magnet ramp rate during acceleration is constrained by the maximum RF voltage available. It may be possible to move injection a little earlier, but the stability and flatness of the injection field are concerns. Considering all these factors we are left with an injection porch that is about $8 \mathrm{~ms}$ long during which RF capture must take place. And just as noteworthy, the RF voltage on this porch must be raised more than required just for capture to accommodate the early ramp rate, which is high in order to allow the cycle to fit in the required $200 \mathrm{~ms}$ interval. Figure 5 shows the cycle.

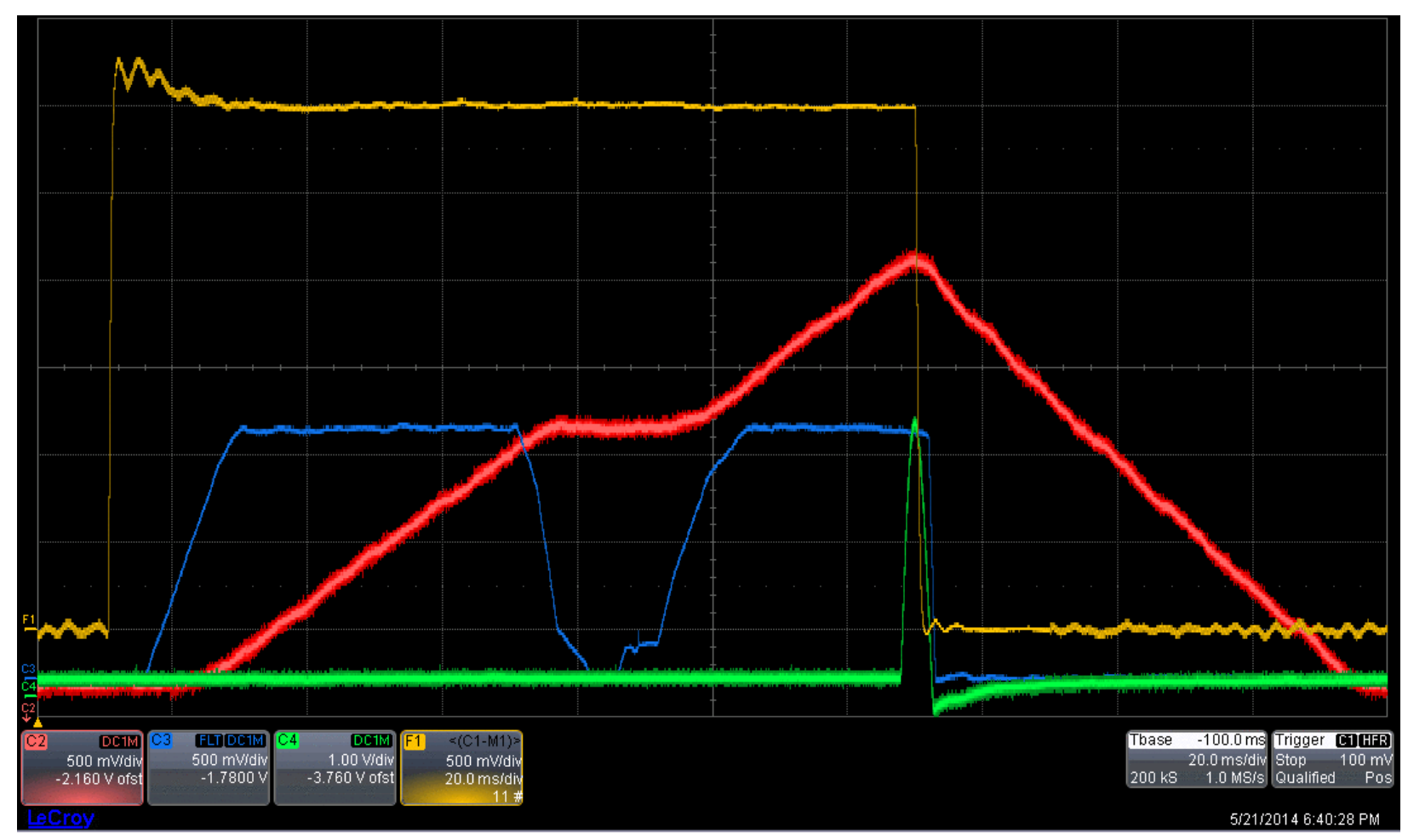

Figure 5: The200 ms Booster cycle ( $20 \mathrm{~ms} /$ division). The orange trace is the normalized current transformer, blue is the $\mathrm{h}=4$ and $\mathrm{h}=1 \mathrm{RF}$ voltage, red is the main magnet current, and green an extraction bump magnet current.

Figure 6 shows the field measured by the hall probe and the reference over the first $20 \mathrm{~ms}$ of the cycle. The measured field plot also shows the field just before Bt0. Note that the field does not follow the reference well over the first $10 \mathrm{~ms}$ of the cycle and that the range in the $y$-axis is about the same in both plots ( $140 \mathrm{~g}$ ). The actual field over that interval changes by $+50 \mathrm{~g}$, the reference by $+4 \mathrm{~g}$ or so. It looks to me that the field does not have enough time to stabilize before Bt0 and undershoots but is able to settle out by injection time. This setup is reasonably stable over the injection porch which runs from Bt0+10.5 ms to about Bt0+18.5 ms.

Figure 7 shows the field and reference around the $15 \mathrm{~ms}$ long merge porch. As in figure 6 the range in the $y$-axis in both plots is about the same. 

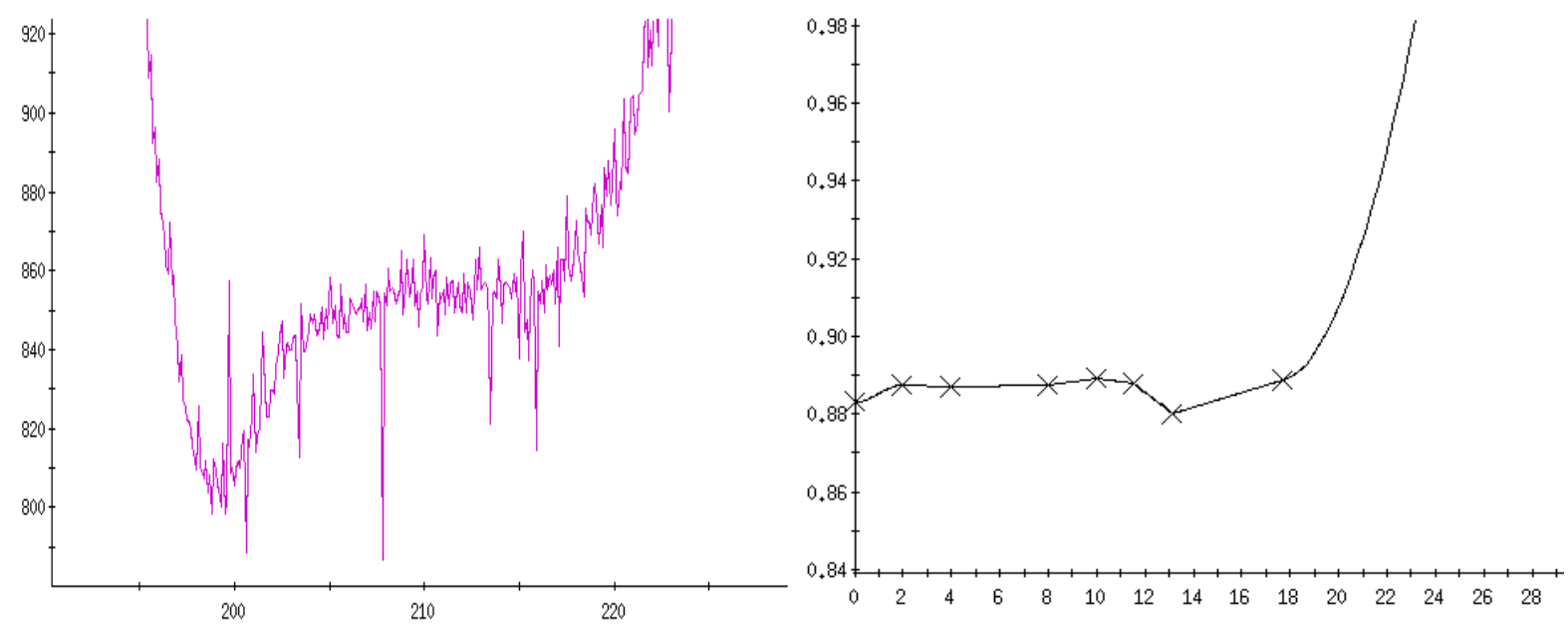

Figure 6: The main magnet hall probe (left) and reference function (right) around the capture porch. In the plot on the left Bt0 (for cycle 2) corresponds to 200 on the $x$-axis, and the $y$-axis is gauss. On the right $\mathbf{0}$ corresponds to Bt0 and the $y$-axis is in kilogauss. In both cases the $x$-axis is in $\mathrm{ms}^{7}$

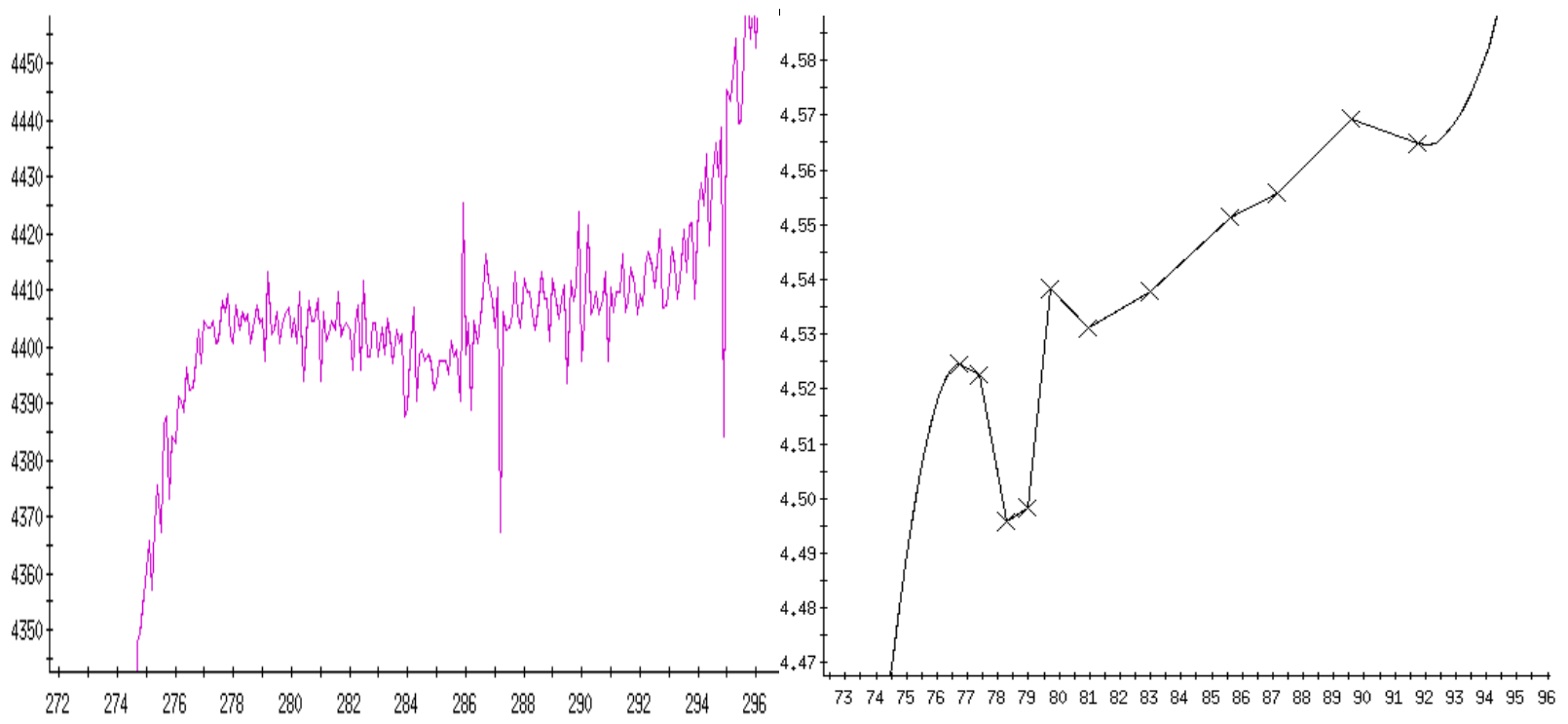

Figure 7: The main magnet hall probe (left) and reference function (right) around the merge porch. In the plot on the left Bt0 (for cycle 2) corresponds to $\mathbf{2 0 0}$ on the $\mathrm{x}$-axis, and the $\mathrm{y}$-axis is gauss. On the right $\mathbf{0}$ corresponds to Bt0 and the $\mathrm{y}$-axis is in kilogauss. In both cases the $\mathrm{x}$-axis is in $\mathrm{ms}^{8}$

\section{Booster Wall Current Monitor Limitations}

Due to the cable that carries the Booster wall current monitor (WCM) signal from building 914 to 911 (where it is measured), the signal available in MCR has an inadequate frequency response for measuring narrow bunch widths. An attempt was made to measure the bunch width in building 914, but it was unsuccessful for reasons unrelated to the frequency response problem. A proper analysis of its frequency response has not been made, but regardless I'm assuming that this issue can be neglected for

${ }^{7}$ Hall probe from Feb 2220141506 elog entry, Reference function is from Feb 222014 1601, user1 archive.

8 Hall probe from March 2520141209 elog entry, Reference function is from March 252014 1601, user1 archive. 
bunch width measurements made very early in the Booster cycle where the bunches are quite wide. The remaining Booster longitudinal emittance measurements are made by looking at the first turn of beam in the AGS on the AGS WCM, whose frequency response is more than adequate for the bunch width at extraction.

I'm basing my confidence on the WCM very early in the cycle primarily on the fact that the falling edge of the bunch falls roughly as fast as its rising edge rises and that a bunch at that time in the cycle should be roughly symmetric. Figure 8 compares an $\mathrm{h}=4$ bunch at various times in the cycle before the merge. The pink trace is at $20 \mathrm{~ms}$ and is roughly symmetric. The other traces from later in the cycle show some asymmetry which I take as largely indicative of an inadequate frequency response. ${ }^{9}$

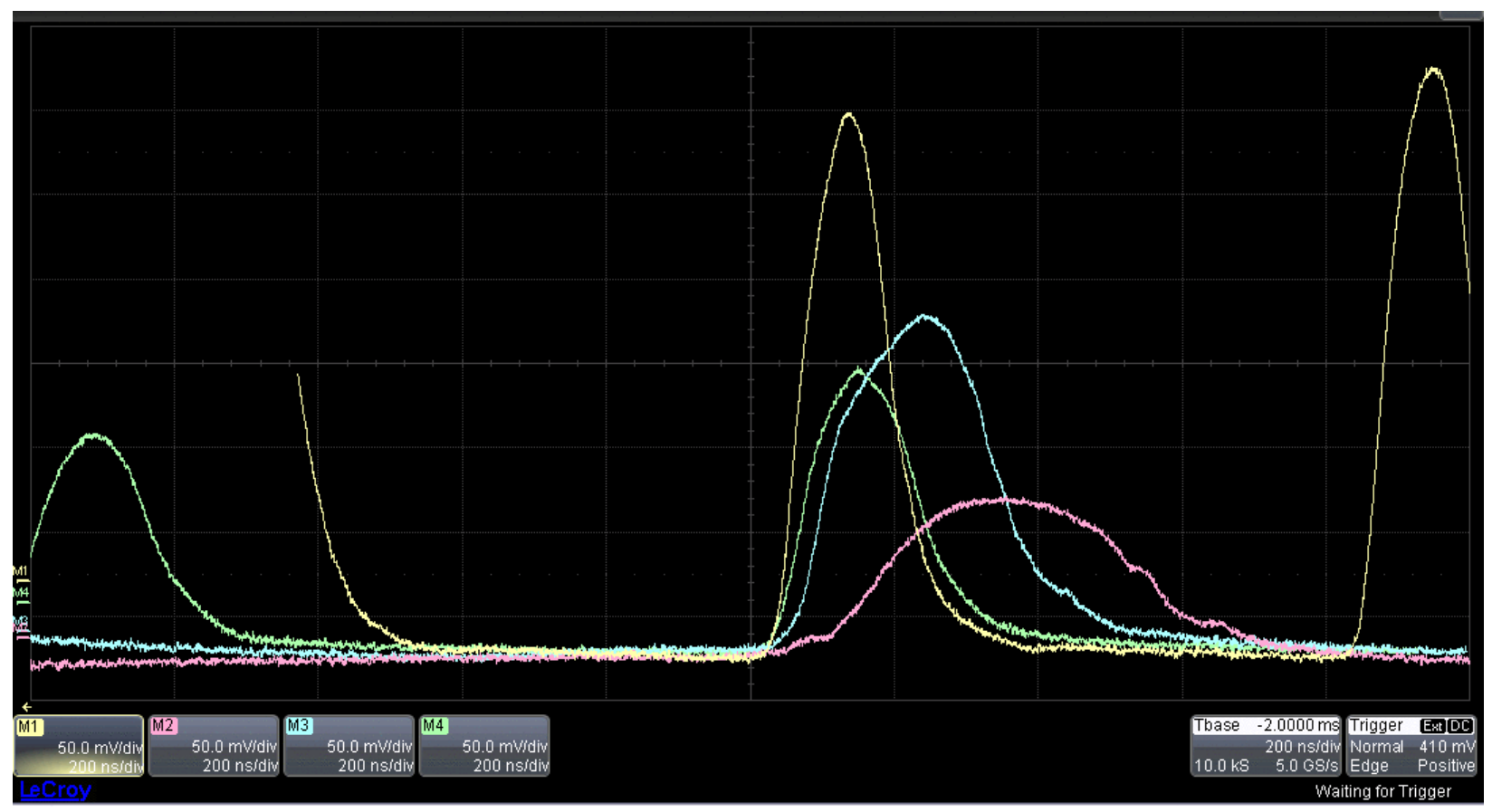

Figure 8: $\mathrm{h}=4$ bunches at different times in the Booster cycle before the merge. Pink is at $20 \mathrm{~ms}$, light blue at $30 \mathrm{~ms}$, light green at $40 \mathrm{~ms}$, and yellow at $50 \mathrm{~ms}$.

Figure 9 shows a bunch in both the Booster at extraction and injection in the AGS using the respective WCMs. Although these were not taken on the same cycle the difference between the 2 illustrates the difference in their frequency responses. Assuming the 2 bunches have the same width, l'd measure the bunch width on the AGS WCM to be about 300 ns (200ns/div) and on the Booster WCM I'd measure about $440 \mathrm{~ns}$, the difference is indicative of the problem. These are $\mathrm{h}=1$ bunches considered here, the difference between the actual and measured widths would be even greater with $h=4$ bunches during a good part of early acceleration, since those bunches are significantly narrower (see figure 8).

\footnotetext{
${ }^{9}$ An accelerating bucket can cause bunch shape asymmetry, and that might account for some of the asymmetry observed in the latter traces.
} 


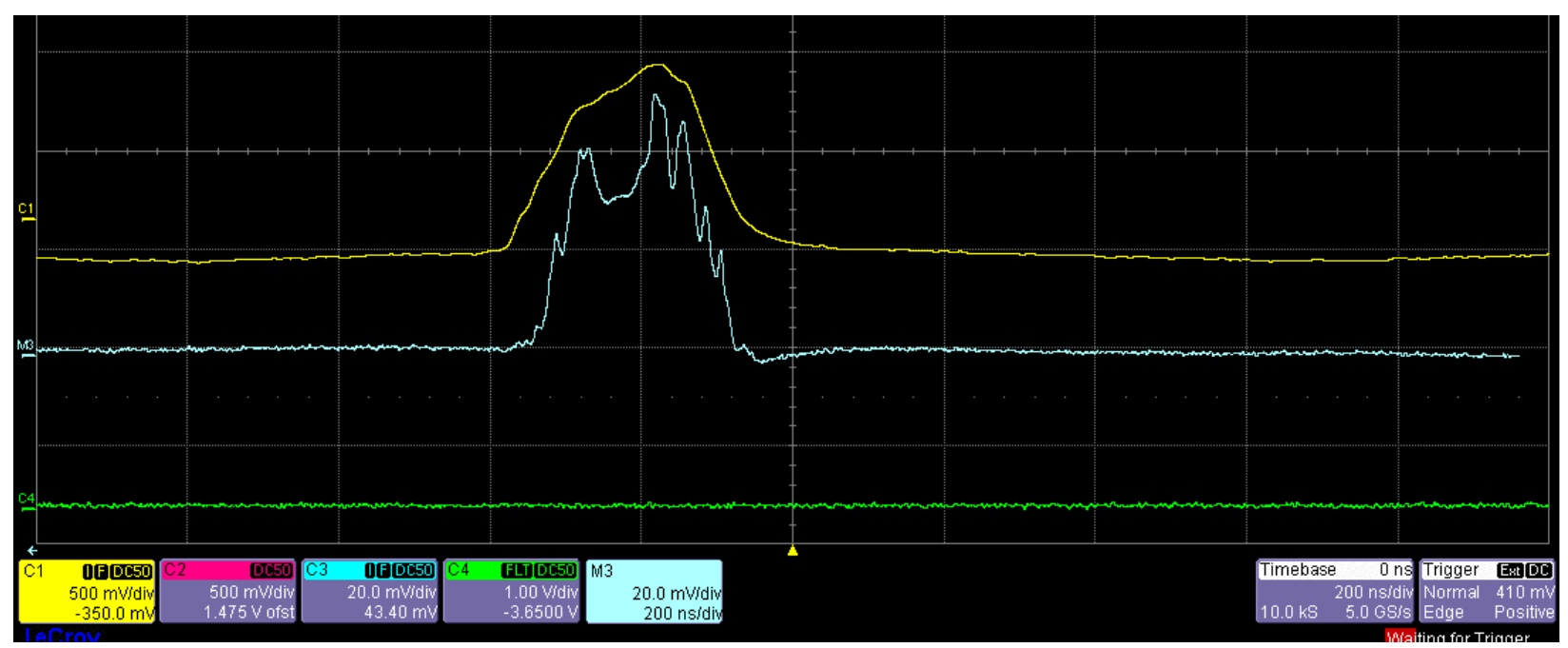

Figure 9: A comparison of a similar bunch as viewed on the Booster (yellow) and AGS (blue) WCM's. The bunch in the Booster is at extraction and on the first turn in AGS (200 ns/div). ${ }^{10}$

\section{Emittance at Booster Extraction}

In general, the Bbat program is used to find the emittance in eVs/nucleon. It accepts various inputs to do the calculation: bunch width, RF Voltage and frequency, ramp rate (dB/dt), etc. The bunch width I try to measure is the full width containing nearly all of the beam. The emittance was measured at extraction for merged and unmerged bunches.

For the case of an unmerged bunch, the measured width was 88.3 ns on the first turn in the AGS (figure 10). The ramp rate $(\mathrm{dB} / \mathrm{dt})$ at extraction was measured using the gauss clock, and the energy is determined from the Booster RF frequency. The synchrotron frequency near extraction was measured by inducing oscillations in the envelope of the WCM signal that have a period of twice the synchrotron period (see figure 11). Once the synchrotron frequency was measured, the RF voltage in Bbat was adjusted until the synchrotron frequency in the program matched the one measured. Since the voltage reference is known, a calibration of the Booster RF voltage reference can be found assuming the response is linear and independent of frequency. The reference voltage was $31.5 \mathrm{kV}$, and the voltage corresponding to the measured synchrotron frequency was $25.2 \mathrm{kV}$ for a calibration of 0.80 . Figure 12 shows the Bbat window for this case where the resulting emittance for 1 bunch is $0.020 \mathrm{eVs} / \mathrm{n}$, which corresponds to a total emittance in the 4 bunches of $0.080 \mathrm{eVs} / \mathrm{n}$.

${ }^{10}$ Jan 24, 20141716 elog entry 


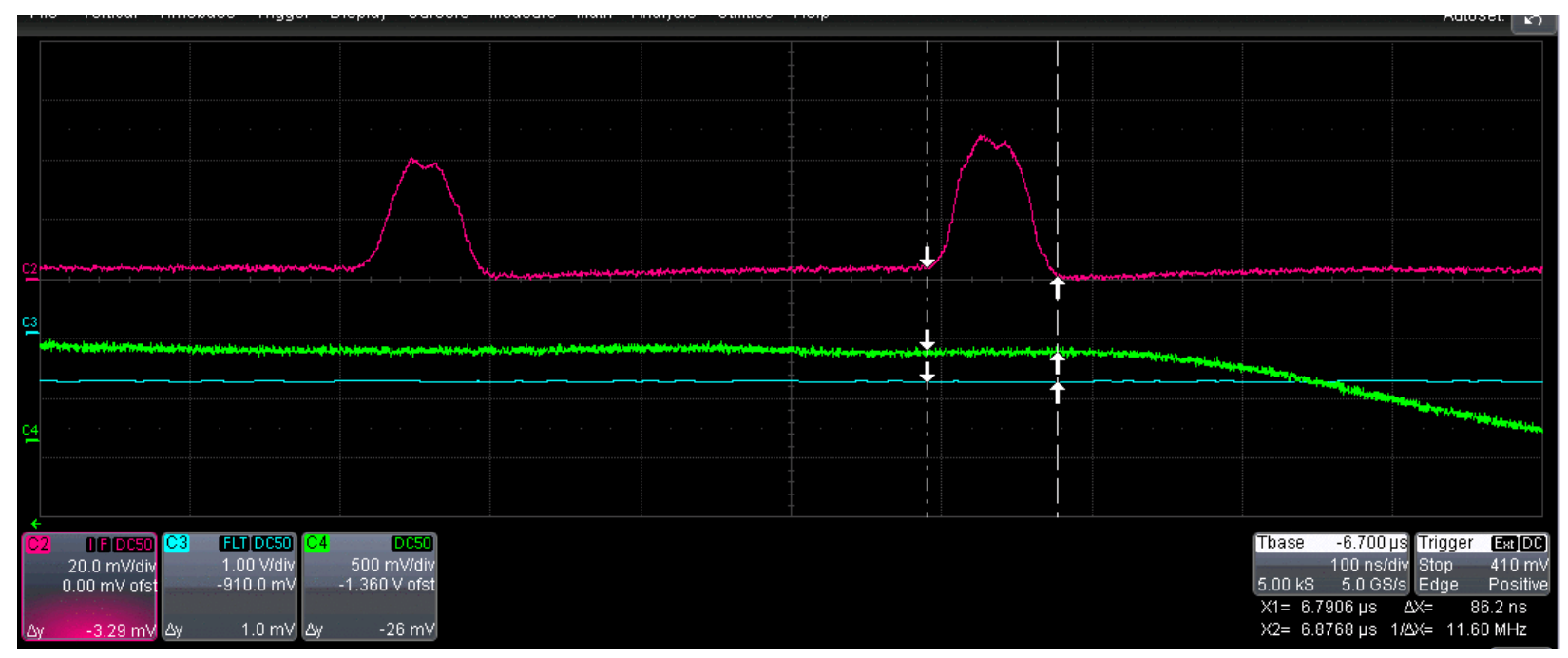

Figure 10: $\mathrm{h}=4$ bunch on first turn in AGS as seen on WCM. An average of 4 measurements was 88.25 ns. ${ }^{11}$

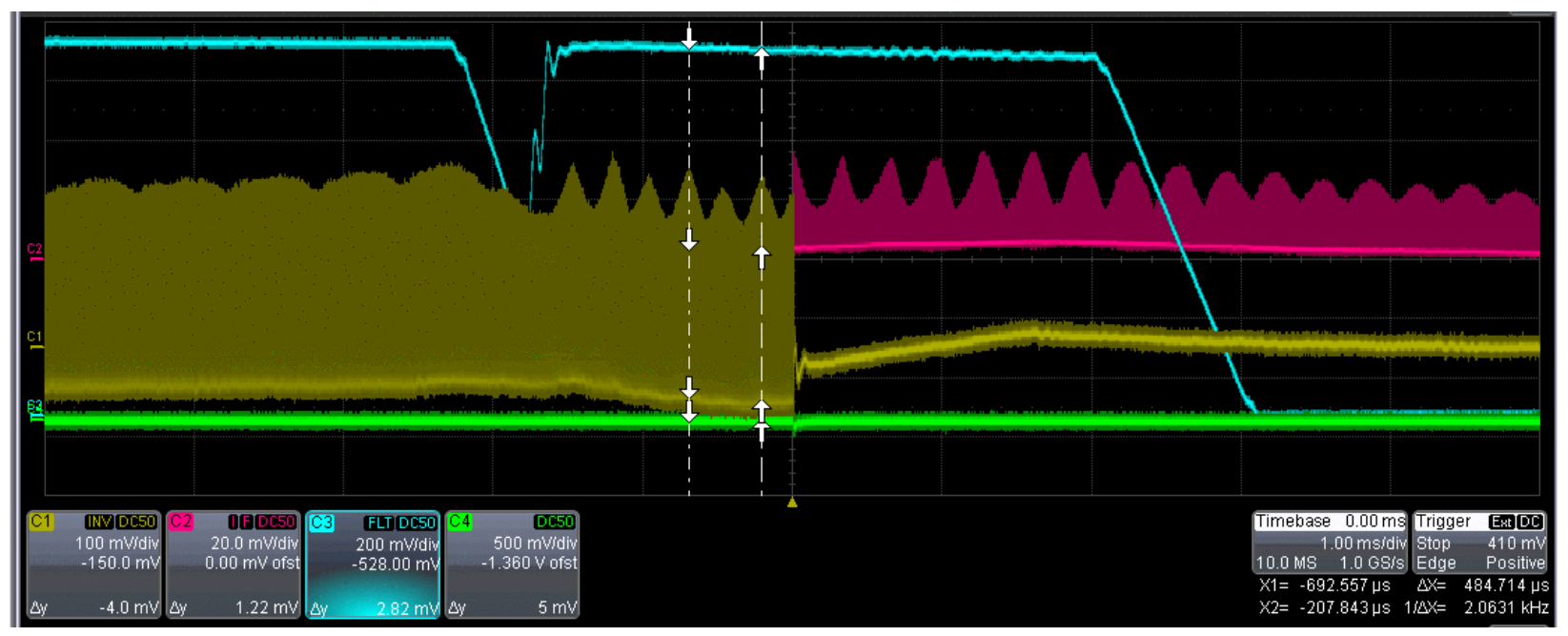

Figure 11: Synchrotron frequency measurement at Booster extraction using synchrotron oscillations on the Booster WCM. The time between 2 revolutions is one synchrotron period, which gives $2.06 \mathrm{kHz}$. The blue trace is an RF cavity voltage signal showing the dip and rapid rise which induces the oscillations. The red trace is the AGS WCM. ${ }^{12}$

In the case of a merged bunch, the measured width was 260 ns on the first turn in AGS (figure 13). With the same RF voltage $(25.2 \mathrm{kV}$ ) this gives an emittance using Bbat of $0.089 \mathrm{eVs} / \mathrm{n}$. That implies that the increase in emittance from the 2 Booster merges is small, on the order of $10 \%(0.089 / 0.080)$. The difference between the 2 measurements is perhaps within their range of accuracy. The 2 measurements were also taken on different days. An assumption used here is that passing through the BtA stripping foil in both cases doesn't affect the width of the first turn in the AGS. Another assumption, especially noteworthy in the $h=1$ case, is that the bunch has equilibrated, which clearly on some level at

\footnotetext{
11 June 242012 Booster-AGS elog entries

12 June 242012 Booster-AGS elog entries
} 
least isn't true. The envelope of the Booster WCM in either case doesn't show large amplitude oscillations near extraction in either case, perhaps on the level of $10-15 \%$ of peak amplitude. ${ }^{13}$

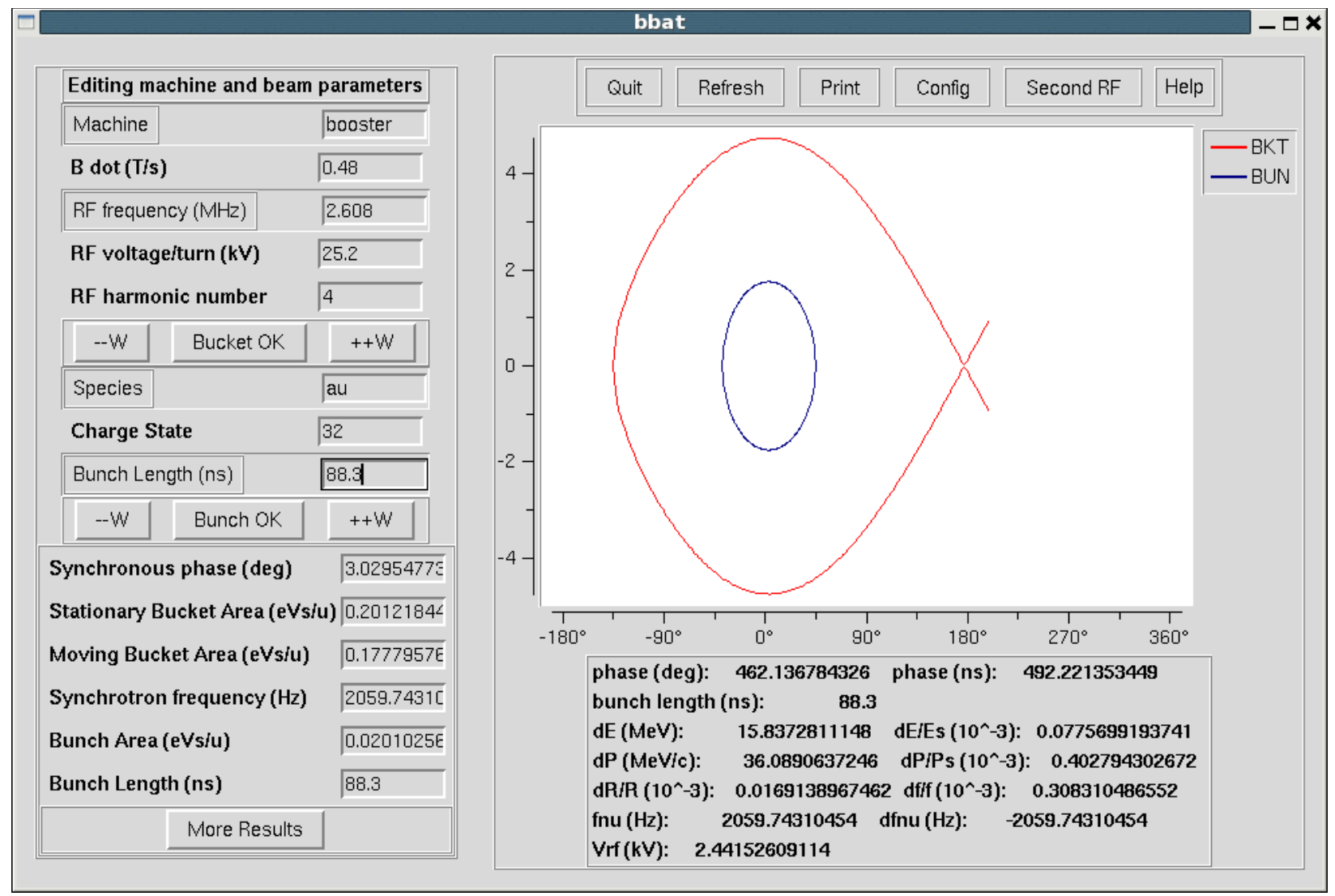

Figure 12: Bbat window for $h=4$ bunch measurement at Booster extraction which gives a Bunch Area, or longitudinal emittance, of $0.020 \mathrm{eVs} / \mathrm{h}$.

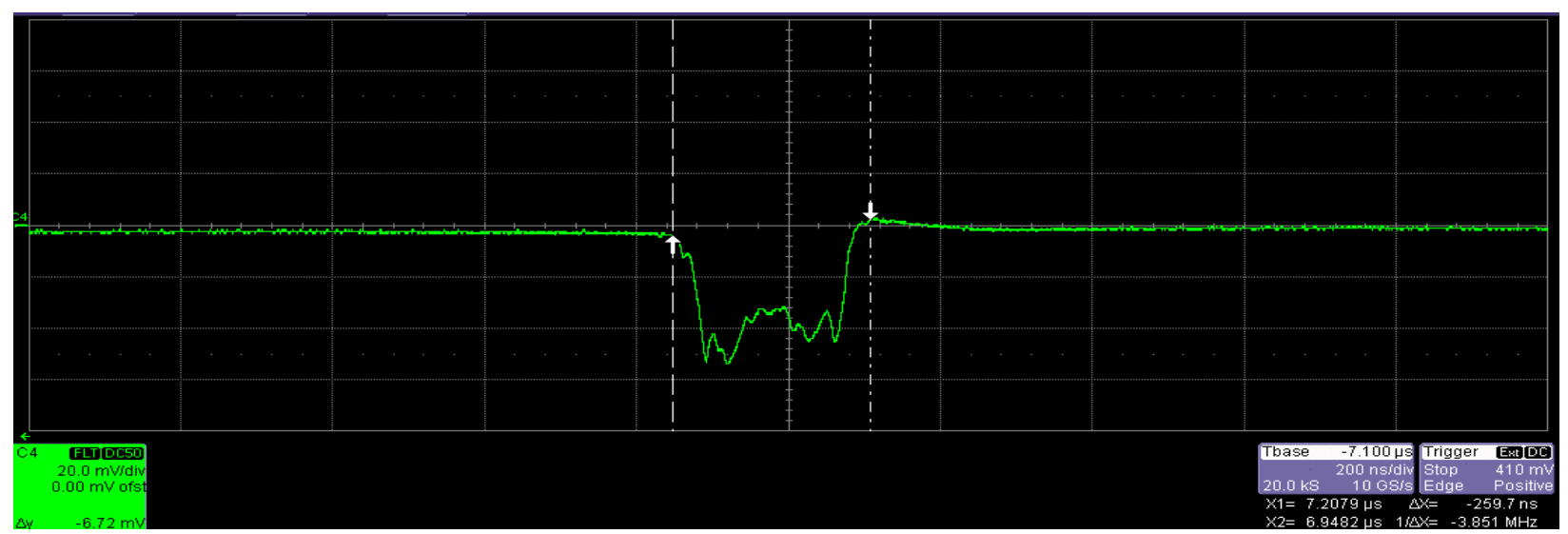

Figure 13: $h=1$ bunch on first turn in AGS as seen on WCM. The measured width is $260 \mathrm{~ns}$ ( $200 \mathrm{~ns} / \mathrm{div}$ ).

${ }^{13}$ In the $\mathrm{h}=4$ case, the AGS first turn width was measured before the synchrotron oscillations were induced. 


\section{Emittance at AGS Injection}

Closely related to the Booster extraction emittance is the AGS injection emittance. They would be the same except for the effect of the BtA foil which increases the bunch's momentum spread. There are 2 ways that the injection emittance was measured. The first way was by measuring the emittance of bunches that had been sitting on the injection porch for some time. The second way was to obtain it from a momentum spread measurement of the injected beam.

\section{Equilibrated Bunch Method}

With a merged bunch, adjusting the RF voltage right at injection so the bucket is as well matched to the bunch as possible, and measuring its width soon after, won't provide an accurate emittance measurement because the bunch hasn't stopped filamenting. The particle distribution needs to be as smooth and constant as possible. A couple of these 'equilibrated' width measurements were made over the run. I'll concentrate on the latter one, made in May, which was taken 1000 ms after injection, but still on the injection porch. In this case, although the bunch is not that smooth, it is much smoother than the one right at injection. As shown in figure 14, its width is $310 \mathrm{~ns} .{ }^{14}$ The synchrotron frequency, $1228 \mathrm{~Hz}$, was measured from oscillations on the envelope of the WCM that were present. From this, Bbat gives an emittance of $0.10 \mathrm{eVs} / \mathrm{n}$ for one bunch. Since each bunch after the AGS merge is comprised of beam from 4 Booster bunches, $4^{*} 0.10 \mathrm{eVs} / \mathrm{n}=0.40 \mathrm{eVs} / \mathrm{n}$ would be the emittance of one bunch after the AGS merge provided that the merge is emittance preserving and all the beam from the 4 bunches is in it.

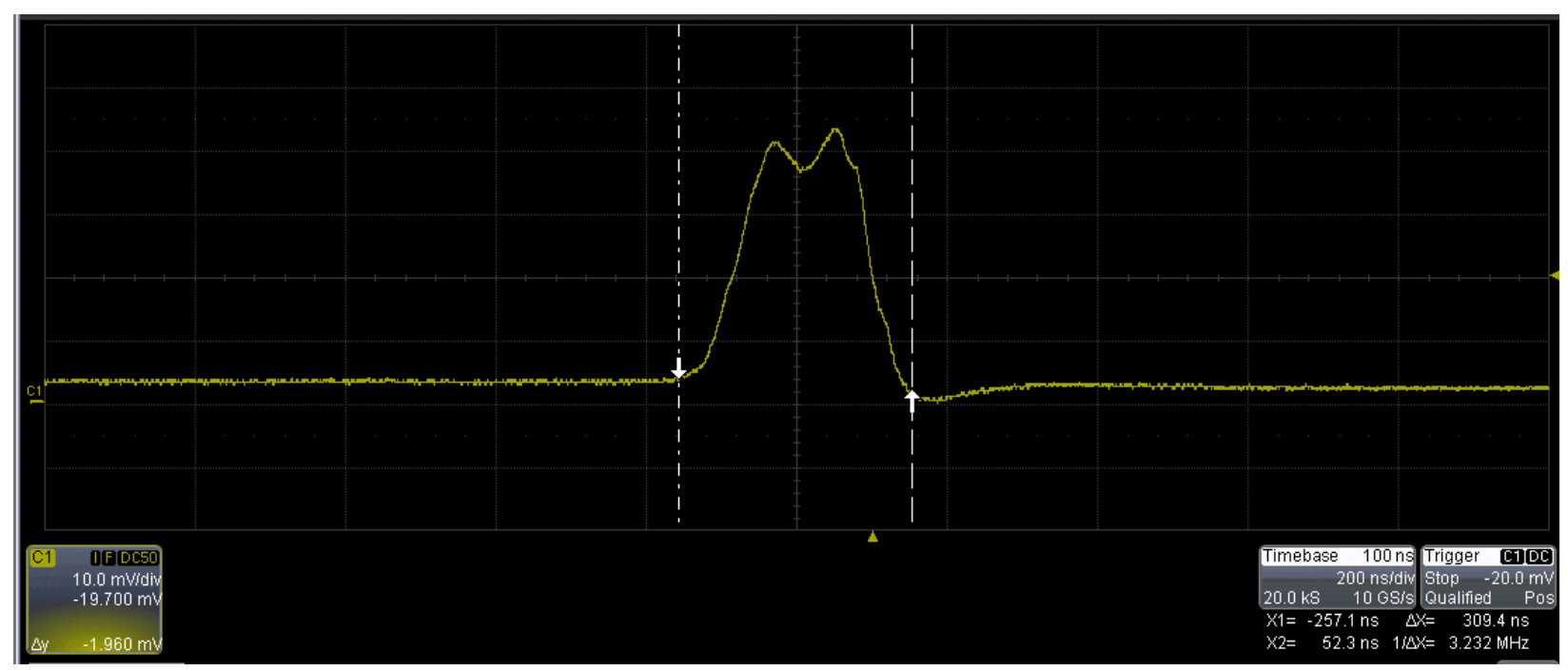

Figure 14: A bunch after $1000 \mathrm{~ms}$ on the AGS injection porch, $310 \mathrm{~ns}$ in width (200 ns/div). ${ }^{15}$

\footnotetext{
${ }^{14}$ The voltage at this time in the cycle is not the injection matching voltage. It has been lowered after injection. That difference accounts, at least in part, for the larger width here compared to right at injection, $310 \mathrm{vs.} 260 \mathrm{~ns}$.

${ }^{15}$ May 520141430 Booster AGS elog
} 


\section{Momentum Spread Method}

By measuring the time it takes the incoming beam to debunch its momentum spread can be measured. I use a formula from AGS Studies Report \#356 to calculate this ${ }^{16}$. This formula is only valid for smooth bunches, which certainly is not the case here. The formula is,

$$
t_{d b}=\frac{\pi-\Delta \phi}{2 \pi f_{0} h|\eta| d p / p}
$$

Where $\mathrm{t}_{\mathrm{db}}$ is the debunching time, $\Delta \phi$ is the half bunch width (in radians), $\mathrm{f}_{0}$ the revolution frequency, $\mathrm{h}$ the harmonic, $\eta$ is the slip factor, and $d p / p$ the (half-width) momentum spread. $t_{d b}$ is the time it takes for the leading edge of a bunch to reach the trailing edge of the adjacent bunch (in this case the same bunch). $h$ refers to the number of evenly spaced bunches in the ring, and here it equals 1 since there is only 1 bunch.

I did 2 debunching measurements on the AGS injection porch. Both were early in the run. I'll concentrate on the latter one. $\eta$ is -0.7949 , the revolution frequency is $163 \mathrm{kHz}$, the half bunch width in radians is [ $282 \mathrm{~ns} / 6.13$ us) $\pi=0.145$. Figure 15 shows the measurement. The RF is off and the mountain range is set to start triggering when the beam is first injected. The time between traces and the gain of the WCM signal is adjusted to get the clearest view of the edges of the beam as it debunches. In an ideal case these edges would be well-defined straight lines. In figure 15 the trace at which the two edges appear to meet is highlighted, and then above the mountain range traces it is also displayed with a higher gain. ${ }^{17}$

In figure 15, the number of traces it takes for the rising and falling edges to meet is estimated by eye to be 58 . There are $60 \mu$ s between traces, so $t_{d b}$ is $3.48 \mathrm{~ms}$. The value for $d p / p$ obtained by solving the above equation for it is $1.06 \mathrm{e}-3$.

Figure 16 shows how I get the emittance of a bunch with that momentum spread and width using Bbat. I set the parameter values on the left to those for AGS injection with a bunch width of 282 $\mathrm{ns}, \mathrm{h}=16$. Then I move the cursors over the bunch graphic and 2 red lines appear. The parameter values of interest below the graphic are those for where the horizontal line is. In particular, "dP/Ps(10^-3):", is the half width $\mathrm{dp} / \mathrm{p}$. I adjust the RF voltage per turn so that this line falls on the top edge of the bunch and reads the desired $\mathrm{dp} / \mathrm{p}$. Then I read off the bunch Area, $0.087 \mathrm{eVs} / \mathrm{n}$. Of course, this technique assumes a smooth distribution, and this distribution is certainly not smooth. For 4 bunches this corresponds to an emittance of $0.35 \mathrm{eVs} / \mathrm{n}$.

\footnotetext{
${ }_{16}^{16}$ AGS Studies Report \#356, "Linac Beam Momentum Spread", Sy Zhang, June 8-9, 1996

${ }_{17}$ This method has a significant subjective element, as do bunch width measurements in general. Error bars can be put on the measurement to reflect that.
} 


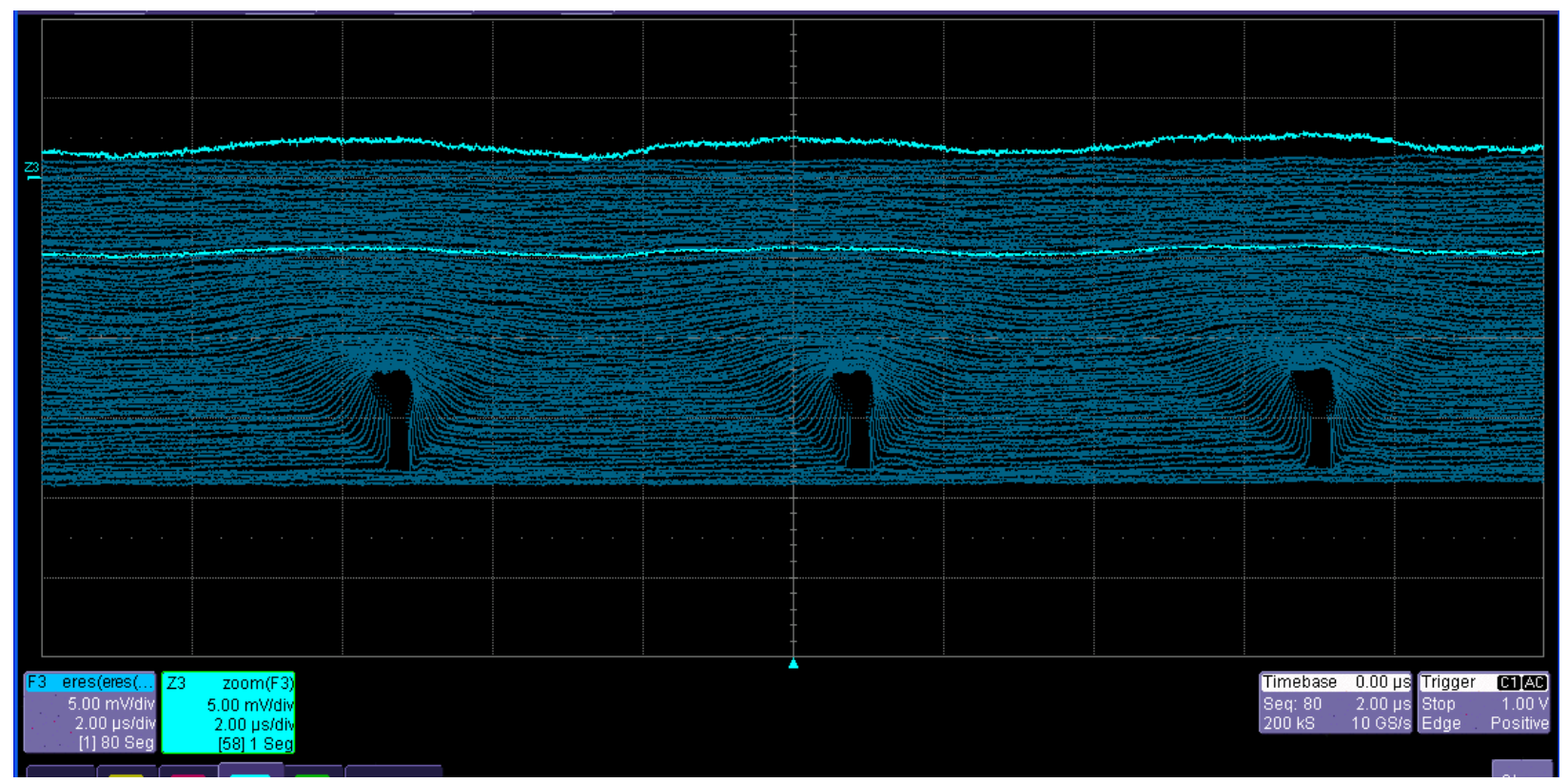

Figure 15: Mountain range display of debunching beam at AGS injection. The highlighted trace is located 58 traces from the start and is where it's estimated that the edges meet. The other lighter trace is that $58^{\text {th }}$ trace set to a higher gain. ${ }^{18}$

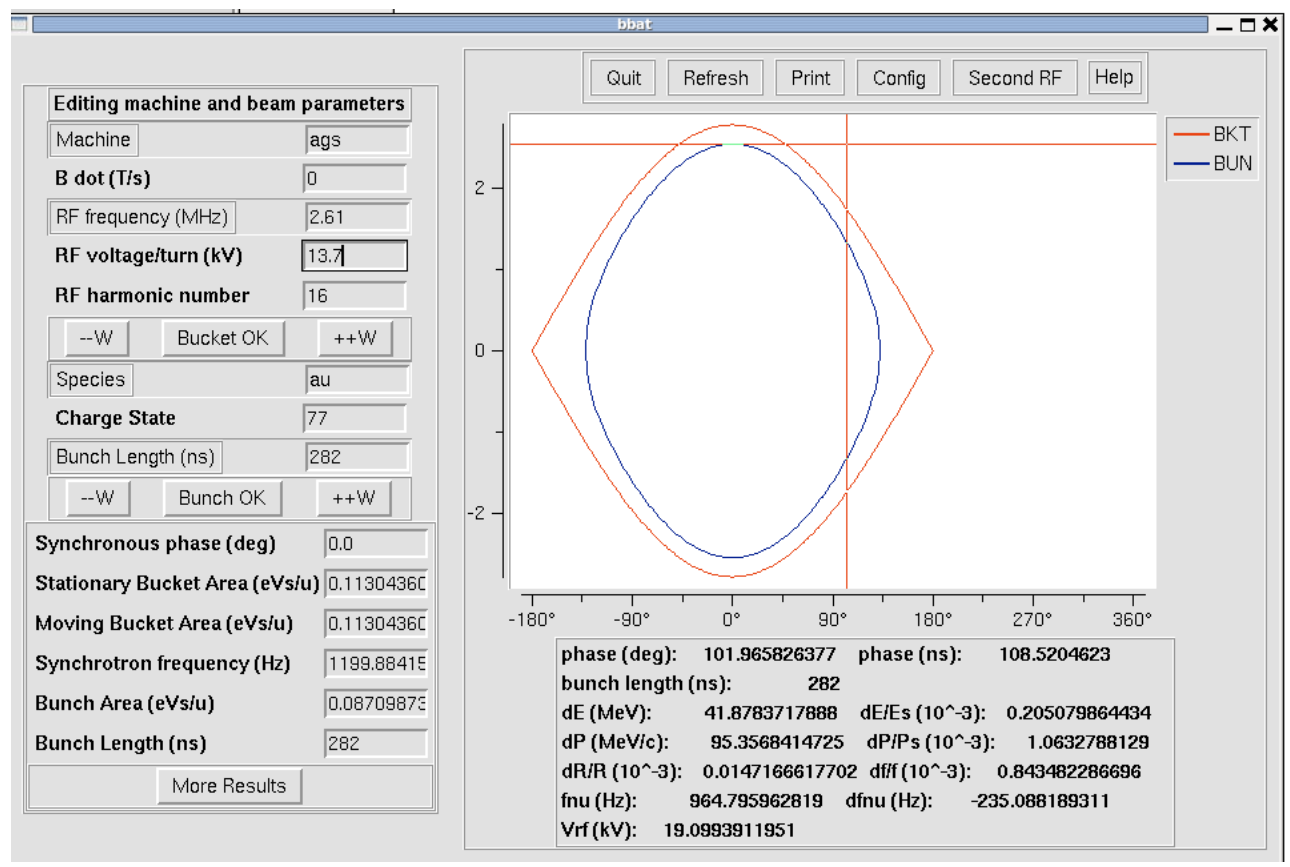

Figure 16: Finding the longitudinal emittance from the momentum spread using Bbat. A half-width $d p / p$ of $1.06 e-3$ and $h=16$ bunch width of $282 \mathrm{~ns}$ corresponds to $0.087 \mathrm{eVs} / \mathrm{n}$. See text for an explanation of how this is done.

The other debunching measurement made 3 days earlier gives a value of $0.086 \mathrm{eVs} / \mathrm{n}$, in good agreement. ${ }^{19}$ If nothing else, the 2 quite different types of measurements give results which are not that

${ }_{19}^{18} \frac{\text { Jan 27, } 20141730 \text { Booster AGS elog entry }}{\text { Jan 24, } 20142206 \text { Booster AGS elog entry }}$ 
far from each other, $0.34-0.35 \mathrm{eVs} / \mathrm{n}$ for the $\mathrm{dp} / \mathrm{p}$ method, and $0.40 \mathrm{eVs} / \mathrm{n}$ for the equilibrated bunch method.

The emittance at Booster extraction was found to be $0.089 \mathrm{eVs} / \mathrm{n}$ for a bunch merged in the Booster, this gives $0.36 \mathrm{eVs} / \mathrm{n}$. This is slightly smaller than the equilibrated bunch emittance in AGS and about the same size as the emittance determined from momentum spread. So, it doesn't appear that the contribution to emittance from the foil is particularly significant, perhaps on the $10 \%$ level.

A similar debunching measurement from run 12 resulted in a $d p / p$ of $1.65 e-3$. With the measured bunch width of $278.4 \mathrm{~ns}$ this gave an emittance of $0.133 \mathrm{eVS} / \mathrm{n}$. ${ }^{20}$ An equilibrated bunch measurement from 2012 found an emittance of $0.14 \mathrm{eVs} / \mathrm{n} .{ }^{21}$ These measurements suggest the Booster beam was smaller this year than it was in run 2012; its $d p / p$ smaller by a factor of $0.0865 / 0.133=0.65$, and its 'equilibrated' emittance by a factor of $0.10 / 0.14=0.71$. Another equilibrated bunch measurement made early in the run, with not as much time given to settle out (199 ms vs. $1000 \mathrm{~ms}$ ) resulted in a per bunch emittance of $0.113 \mathrm{eVs} / \mathrm{n}$, somewhat larger, corresponding to a factor of 0.81 smaller than the run 12 result.

\section{Emittance of a Merged AGS Bunch}

To find the emittance after the merge I measured it at a time in the cycle when only the L10 $(h=4)$ cavity is on and the merge is complete. Normally, the $h=8$ voltage would also be on at that time, and phased for the bunch squeeze, but it is set to 0 for this measurement. The time At0+1596 ms was used, it is before the $\mathrm{h}=12 \mathrm{RF}$ and the RF loops come on, and while the beam is still on the injection porch. This was done on AGS user 2 (used for low energy RHIC injection), but the AGS cycle is the same up to this point.

Figure 17 shows the bunch width measurement (1000 ns) and Bbat calculation. The bunch is reasonably smooth, but still a synchrotron frequency measurement from the WCM envelope was possible without trying to induce oscillations $(436 \mathrm{~Hz})$. The result is $0.428 \mathrm{eVs} / \mathrm{n}$, which since it was 0.40 $\mathrm{eVs} / \mathrm{n}$ before the merge, suggests there is not much emittance growth due to it. ${ }^{22}$ Though it could easily be argued that since the beam is filling the bucket the actual voltage would be higher than what's inferred here from the synchrotron frequency and so the emittance is actually larger than this.

\section{Emittance During the AGS Ramp and on the Flattop}

One thing to keep in mind with these measurements is that they were generally taken at different times during the run. However, in early February a number of them were taken within a couple days of each other. Instead of measuring the synchrotron frequency $\left(f_{\text {synch }}\right)$ to find the RF voltage, an estimated RF voltage derived from the RF reference voltage was often used. Also, it was assumed that for a given voltage reference the voltage doesn't change, so many of the $f_{\text {synch }}$ measurements that were

\footnotetext{
20 Jun 1320121725 Booster AGS elog entry

21 Jun 1920121511 Booster AGS elog entry

22 Feb 120141705 Booster AGS elog entry
} 
made were not taken at the same time as the width measurements. The estimated voltage I use is 0.795 times the total reference voltage, where that is the sum of the active cavity references times 4 (the number of voltage gaps/cavity). In what follows I'll try to compare the voltage from the synchrotron frequency with that from the references when both sets of data are available.

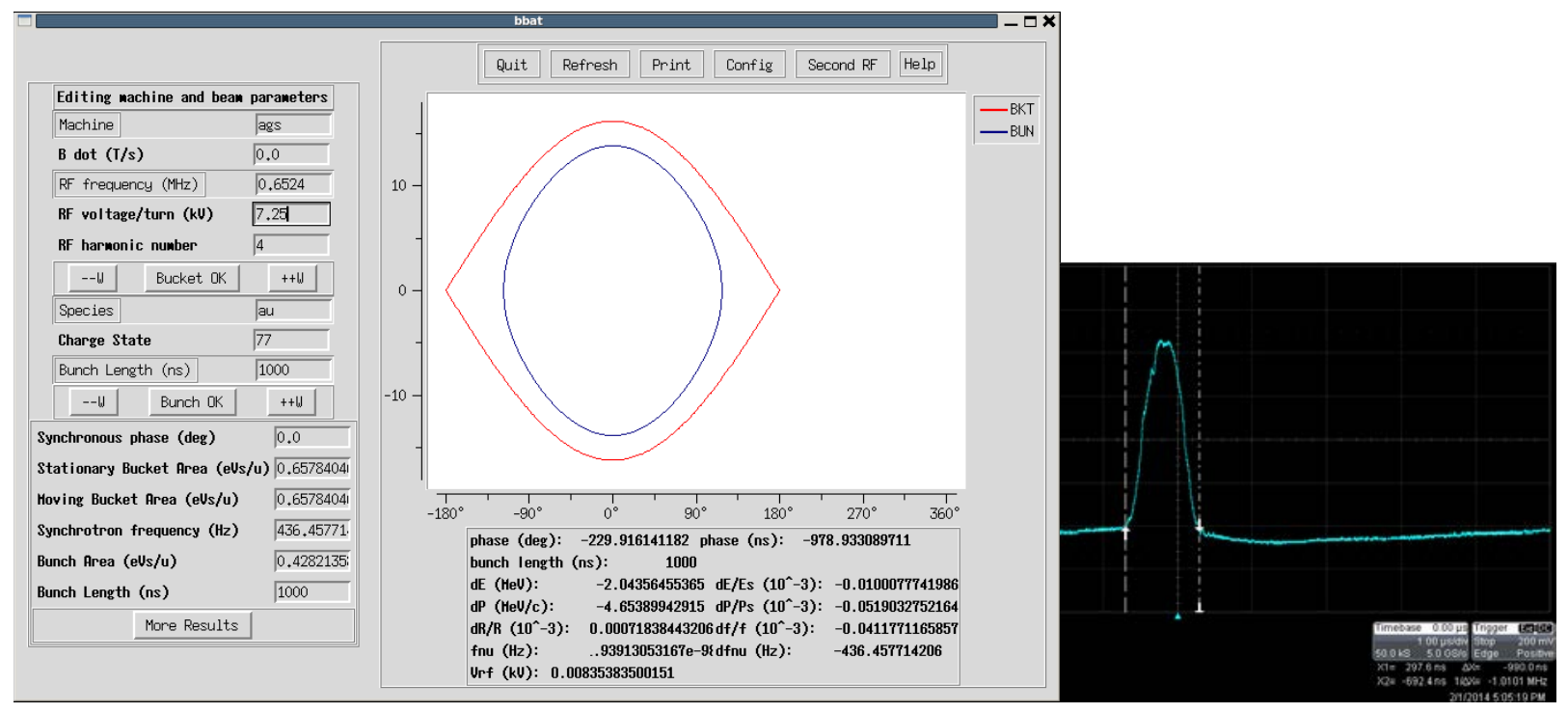

Figure 17: Bunch width and emittance calculation for $h=4$ after the merge. Bunch width of 1000 us, and measured synchrotron frequency of $436 \mathrm{~Hz}$ give $0.428 \mathrm{eVs} / \mathrm{n}$.

\section{Background on the AGS Main Magnet Cycle}

There were a lot of changes, particularly to the AGS main magnet, during the course of this run that make it hard to keep track of the exact state of the AGS at any given time, so a brief outline of the major changes is likely in order. The run began in January with the same AGS main magnet function and Siemens motor generator configuration used in run 12 . There was initially an approximately $20 \%$ loss at the time in the ramp when the transfer from the flattop voltage to the pulsed voltage rectifier bank occurs. ${ }^{23}$ This transfer occurs when the ramp rate reaches a certain value. By keeping the early ramp rate below some level the field at which it occurs can be raised. The main magnet function was modified on Jan $30^{\text {th }}$ to make the transfer field higher and therefore occur later in the ramp. This change greatly reduced the loss at the transfer, and had the unintended consequence of also reducing another large loss right at the beginning of the ramp. ${ }^{24}$ It resulted in a slower early ramp except right at the beginning of it, where it was actually slightly faster. After this change the transfer moved from 1963 to $2090 \mathrm{~ms}^{25}$

\footnotetext{
${ }^{23}$ There was a loss around this time in the cycle in run 12, but it was about an order of magnitude smaller.

${ }^{24}$ This loss was also about $20 \%$, after the change, which included some adjustment of the RF voltage there; it was about a third of that. In run 12 this was a persistent loss about the same size as a Booster transfer ( $\sim 12 \%$ of the beam). In run 12, if the bucket squeeze was removed this loss would disappear, but there was no net benefit because the baby bunches would get much larger.

${ }^{25}$ The $\mathrm{F}$ bank voltage limit was also raised from 1500 to $1600 \mathrm{~V}$ which allowed the transfer time to be $5 \mathrm{~ms}$ later and its field to be a little higher than they would've been otherwise.
} 
On Feb $19^{\text {th }}$, during the low energy run, the main magnet was switched from the Siemens to Westinghouse motor generator. Around March $10^{\text {th }}$ we switched back to the high energy setup, but reverted back to a magnet function with the same early ramp as before the Jan 31 changes. The transfer was back at $1963 \mathrm{~ms}$, and the function before $2278 \mathrm{~ms}$ was the same as it was before Jan 31. It had a slower ramp after $2278 \mathrm{~ms}$ to accommodate Westinghouse. ${ }^{26}$ On March $18^{\text {th }}$, the function was modified again to be more like the one loaded on Jan 30 for the part of the ramp before $2278 \mathrm{~ms}$ (the transfer now occurring at $2098 \mathrm{~ms}$ ). This is basically the function that was used for the remainder of the run. During the course of all this it was noticed that the voltage ripple was less at, and after, the transfer when using the Westinghouse. With the Westinghouse and the later transfer time the loss at the transfer was now completely gone.

On April $3^{\text {rd }}$ the main magnet was switched back to the Siemens, but the low voltage tap used for running with Westinghouse was still kept because it was thought, correctly, that the high voltage tap normally used for Siemens was causing the larger voltage ripple. The main magnet function itself remained the same.

On May $2^{\text {nd }}$ the switch back to using the high voltage tap took place. At the same time, the AC phase loop, whose use resulted in less loss at the transfer, was implemented for the first half of the ramp. Before transition the RF was switched back to radial control. In this state there was a small but noticeable loss at the transfer (1-1.5\%), before this switch there was not. This is how things remained for the rest of the run.

\section{Ramp and Flattop Emittance Measurements}

Table I contains the data for emittance measurements taken on the ramp and at flattop on February $1^{\text {st }}$ and $3^{\text {rd }}$. They were taken on the normal RHIC user (user 1 ) with the Siemens motor generator where the transfer from the flattop voltage back to the pulsed voltage bank occurs at 2090 $\mathrm{ms}$ and the radial loop was used with radial zeroing. ${ }^{27}$ Also, though it's not expected to matter, there were only 4 Booster transfers during this time, providing beam for only one final AGS bunch.

The emittances using estimated voltage $\left(\varepsilon_{\text {ref }}\right)$ and $f_{\text {synch }}\left(\varepsilon_{\text {synch }}\right)$ are both shown when available, and appear to be in pretty good agreement. The emittance appears to stay roughly constant and close to that obtained just after the merge until somewhere between 2100 and $2250 \mathrm{~ms} .{ }^{28}$ From there it grows from 0.40 to a final value of $0.58 \mathrm{eVs} / \mathrm{n}$ at flattop. Transition is at about $2630 \mathrm{~ms}$. Some of the values during the ramp are actually higher than on the flattop, which is inconsistent since there is no

\footnotetext{
${ }^{26}$ The loss at transfer was much smaller than it was back in January because the voltage transient with the Westinghouse is smaller. The loss right at the ramp was apparently smaller than before Jan 31 as well. The reason for that is unclear.

${ }^{27}$ Radial zeroing is a feature of the new LLRF system which keeps the radial loop from introducing a transient in the radius when it turns on.

${ }^{28}$ Also, the fact that these emittance values are close to the one measured just after the merge with only $h=4$ on, and there isn't much beam loss between them, adds confidence to that measurement. The concern was that the measurement just after the merge may have been too low because it used only the synchrotron frequency and the bucket is full there.
} 
significant beam loss over that period. But the trend towards gradually higher $\varepsilon$ values after $2100 \mathrm{~ms}$ or so appears to be significant. Transition is at about $2630 \mathrm{~ms}$. There's no obvious indication of any transition related growth since the final emittance is no higher than that measured at $2560 \mathrm{~ms}$.

\begin{tabular}{|l|l|l|l|l|l|l|}
\hline Time $(\mathrm{ms})$ & $\begin{array}{l}\mathbf{d B} / \mathbf{d t} \\
(\mathrm{g} / \mathrm{ms})\end{array}$ & $\begin{array}{l}\mathbf{0 . 7 9 5}(\mathrm{kV}) \\
\left(17 \mathbf{V}_{\text {ref }}\right.\end{array}$ & $\mathbf{V}_{\text {synch }}(\mathrm{kV})$ & $\begin{array}{l}\text { Bunch width } \\
(\mathrm{ns})\end{array}$ & $\begin{array}{l}\boldsymbol{\varepsilon}_{\text {ref }} \\
(\mathrm{eVs} / \mathrm{n})\end{array}$ & $\begin{array}{l}\boldsymbol{\varepsilon}_{\text {synch }} \\
(\mathrm{eVs} / \mathrm{n})\end{array}$ \\
\hline 1800 & 0 & 121 & - & 383.1 & 0.42 & - \\
\hline 1900 & 0 & 192 & - & 328.4 & 0.43 & - \\
\hline 2000 & 1.5 & 192 & - & 257 & 0.40 & - \\
\hline 2100 & 2.5 & 212 & - & 184.5 & 0.40 & - \\
\hline 2250 & 4.15 & 221 & 200 & 132.5 & 0.40 & 0.38 \\
\hline 2400 & 10.5 & 221 & 206.7 & 82.1 & 0.55 & 0.53 \\
\hline 2560 & 13.8 & 184 & - & 55.7 & 0.60 & - \\
\hline 2700 & 19.0 & 184 & 178.5 & $28.9 *$ & 0.64 & 0.62 \\
\hline 3100 & 11.4 & 184 & 172.5 & $27.6 *$ & 0.75 & 0.72 \\
\hline
\end{tabular}

Table I: Emittance measurements after the merge in the AGS. The $3^{\text {rd }}$ column is the estimated RF voltage using the prescription in the text, the $4^{\text {th }}$ column is RF voltage determined from the synchrotron frequency and Bbat, the $6^{\text {th }}$ column is emittance calculated using the estimated voltage, and the last column is the emittance calculated using the synchrotron frequency. * indicates that the width was found by multiplying the width of the first half of the bunch and multiplying it by 2 .

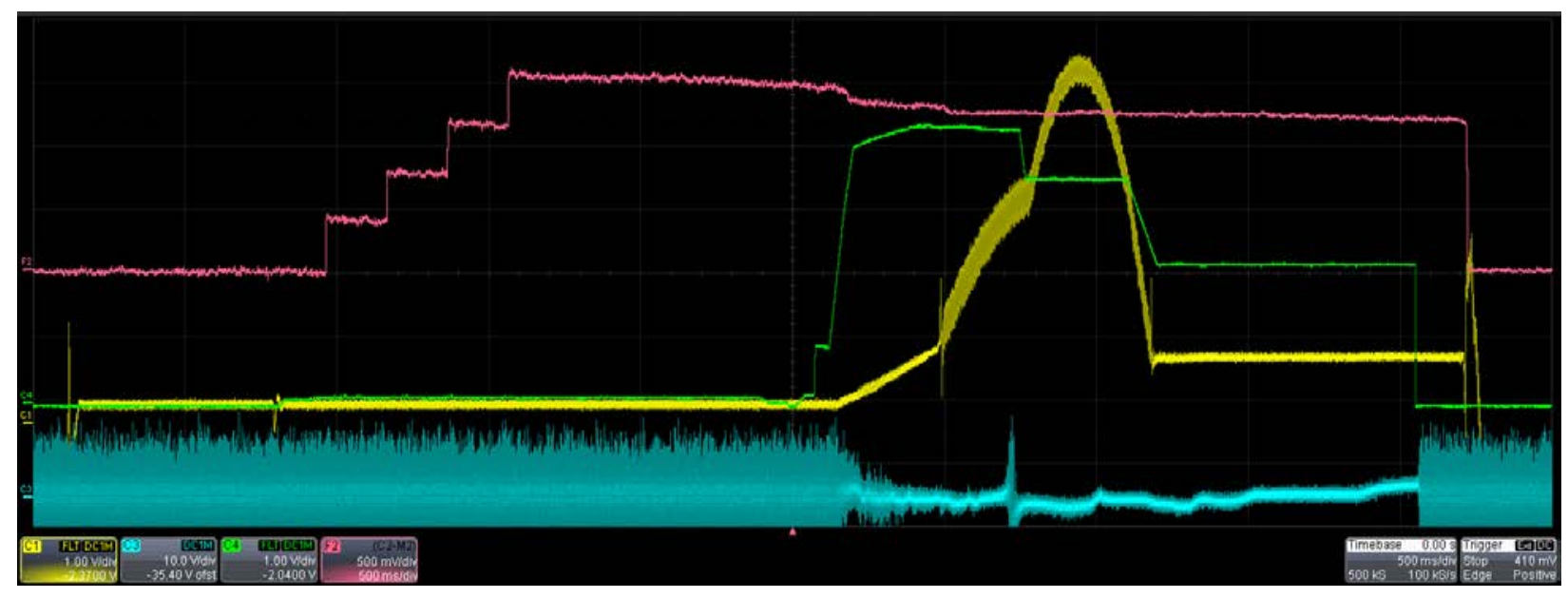

Figure 18: The AGS cycle as it appeared around the time of these measurements showing the loss at the beginning of the ramp, and at Flattop to Pulsed bank transfer. The trigger is At0+1600 ms ( $500 \mathrm{~ms} /$ div). The red trace is the AGS normalized current transformer, yellow is main magnet voltage, green is the RF detected vector sum, and blue is a horizontal bpm signal.

Figure 18 shows the AGS cycle; note the spike in the magnet voltage at the time of $\mathrm{F}$ to $\mathrm{P}$ bank transfer, and the larger amount of ripple in the signals afterwards. The loss at the beginning of the ramp and at bank transfer can be seen. The loss at the transfer gets worse if the RF voltage there is lowered and it is as high there as permitted. 
Figure 19 shows the bunch to bucket phase and radial average signals over a $70 \mathrm{~ms}$ period roughly centered at the transfer time from the evening of Feb 1 . The large amount of structure on both traces begins at the time of the transfer and gradually decreases. Given the lack of any other obvious candidates, and that it seems reasonable to think that this kind of structure could cause emittance growth, the transfer and the ripple on the Pulsed bank seem to me the most likely mechanism for it. Looking at the mountain range over this period though it wasn't obvious that the bunches were being jostled around.
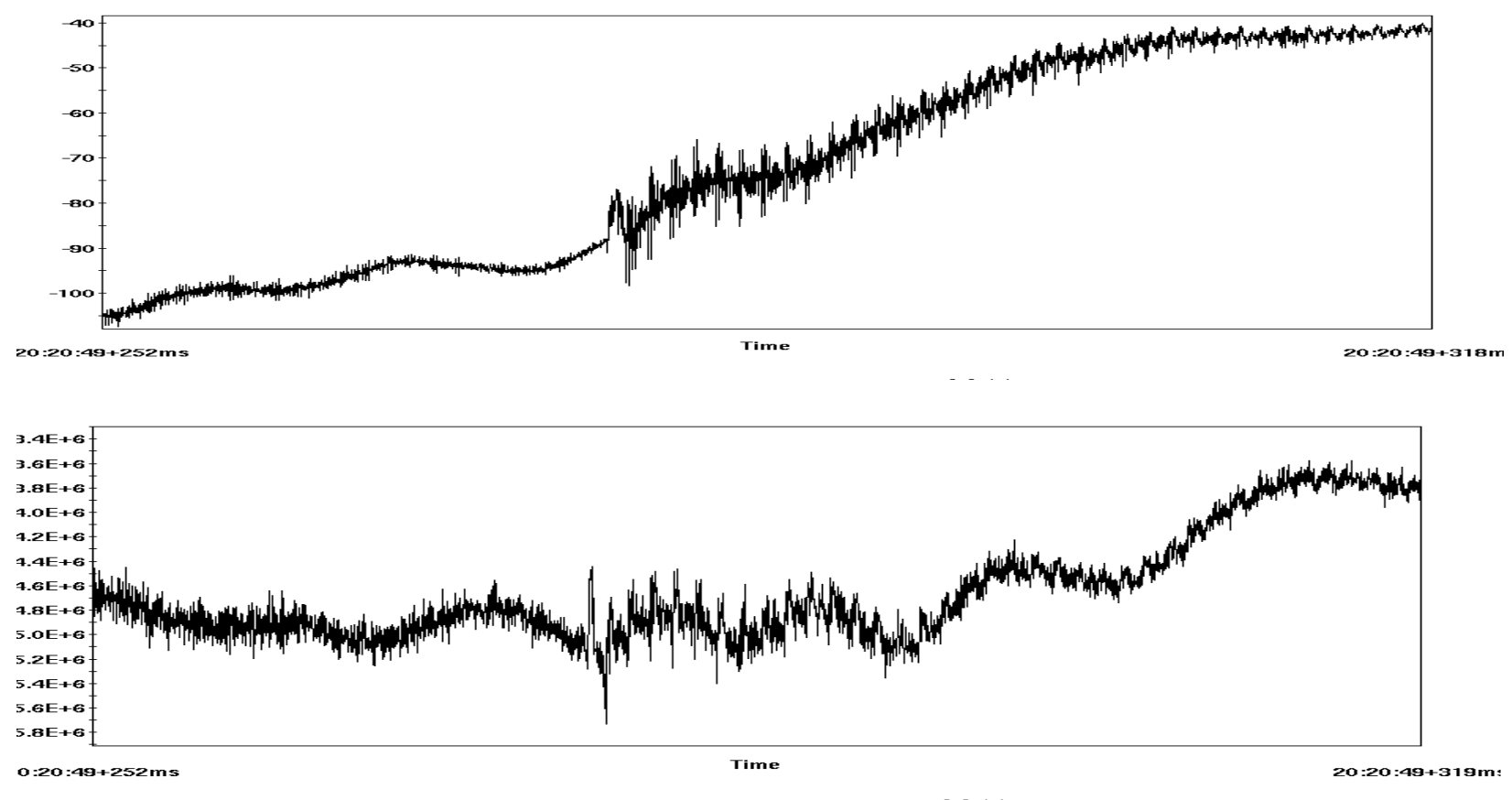

Figure 19 Bunch to bucket phase (top) and radial average during a $70 \mathrm{~ms}$ interval centered on the $\mathrm{F}$ to $\mathrm{P}$ bank transfer, on Feb 1 around the time the ramp emittance measurements were taken.

Although the initial transfer causes the largest glitch, apparently responsible for the beam loss at that time, the larger voltage and therefore field ripple afterwards might explain the gradual growth in the emittance. One might expect its effect to get smaller as the field increases since the amplitude of the oscillations in the field are roughly proportional to the voltage ripple, but the net effect on the beam is more likely to be related to $1 / \mathrm{B}^{*} \mathrm{~dB} / \mathrm{dt}$ (not just $\mathrm{dB} / \mathrm{dt}$ ). Its effect would also be related to how close the magnet ripple frequency components are to a harmonic of the synchrotron frequency. The synchrotron frequency is changing though the ripple frequencies are not.

The fact that the emittance just after the transfer at 2100ms isn't larger is a bit puzzling though. Perhaps the initial transient at transfer mainly causes loss from beam spilling out of the bucket due to a higher $\mathrm{dB} / \mathrm{dt}$, but doesn't contribute to the emittance growth, yet the extended time the bunches are oscillating after the transfer does cause growth. It also seems to be true that the emittance continues to grow after these oscillations have largely gone away. For instance, the emittance seems to grow from 0.53 to $0.62 \mathrm{eVs} / \mathrm{n}$ during the time between 2250 and $2560 \mathrm{~ms}$. 
It's also puzzling that the emittance measured just before flattop is larger than on the flattop ( 0.72 at $2700 \mathrm{~ms}$ and 0.58 at $3100 \mathrm{~ms}$ ). This leads one to suspect measurement errors. One issue is that the frequency response of the AGS WCM also gets to be a problem as the bunches get narrower. They start to look asymmetric and so their widths are calculated by multiplying the half width of the rising edge by 2 for the last 3 times in the cycle (2560, 2700, and $3100 \mathrm{~ms})$.

\section{More Flattop Measurements}

Table II shows additional flattop emittance $(\varepsilon)$ measurements made during the course of the run, where the particular running condition is also summarized. The measured $\varepsilon$ over the course of the run varied from about 0.58 to $0.75 \mathrm{eVs} / \mathrm{n}$. There's not much of an obvious trend in the data. Note that a loss at the bank transfer, or beginning of the ramp, could contribute to a lower $\varepsilon$ because the outside of the bunch is lost, and that's not a preferable state. From May 2 onward the AC phase loop was used for the early ramp, $\varepsilon$ in that state was measured at $0.65 \mathrm{eVs} / \mathrm{n}$. The Apr 23 and May 2 data also may show that the AC phase loop gives a slightly smaller $\varepsilon(\sim 10 \%)$. It also reduces the loss at the bank transfer.

\begin{tabular}{|l|l|l|l|l|l|l|l|}
\hline Date & $\begin{array}{l}\text { Motor } \\
\text { Generator }\end{array}$ & $\begin{array}{l}\text { Voltage } \\
\text { Tap }\end{array}$ & $\begin{array}{l}\text { F to } \mathbf{P} \\
\text { Transfer }\end{array}$ & Loop & $\begin{array}{l}\mathbf{V}_{\text {synch }} \\
(\mathrm{kV})\end{array}$ & $\begin{array}{l}\text { Bunch } \\
\text { width (ns) }\end{array}$ & $\boldsymbol{\varepsilon}(\mathrm{eVs} / \mathrm{n})$ \\
\hline Jan 31 & Siemens & High & $2090 \mathrm{~ms}$ & b.c. & 118 & 29.4 & 0.66 \\
\hline Feb 3 & Siemens & High & $2090 \mathrm{~ms}$ & b.c. & 118 & 27.6 & 0.58 \\
\hline Mar 13 & Westinghouse & Low & $1963 \mathrm{~ms}$ & b.c. & 143.3 & 27.3 & 0.63 \\
\hline Mar 21 & Westinghouse & Low & $2098 \mathrm{~ms}$ & b.c. & 192 & 25.8 & 0.65 \\
\hline Apr 3 & Siemens & low & $2098 \mathrm{~ms}$ & b.c. & 190 & 26.3 & 0.67 \\
\hline Apr 23* & Siemens & Low & $2098 \mathrm{~ms}$ & ac phase & 191 & 26.75 & 0.70 \\
\hline Apr 23 & Siemens & Low & 2098 & b.c. & 191 & 27.7 & 0.75 \\
\hline May 2 & Siemens & High & 2098 & ac phase & 193 & 25.85 & 0.65 \\
\hline May 2* & Siemens & High & 2098 & b.c. & 193 & 27.16 & 0.72 \\
\hline
\end{tabular}

Table II: Flattop $\varepsilon$ measurements during the course of the run. "b.c." means on beam control (the radial loop and normal phase loop) during the entire ramp, "ac phase" means on the AC phase loop at the beginning of the run and switching to beam control before transition. * indicates an atypical running condition.

For comparison, during run 12 the flattop $\varepsilon$ was about $0.54 \mathrm{eVs} / \mathrm{n}$, smaller than this run. ${ }^{29}$ But it is important to note that the losses, particularly at the beginning of the ramp were much larger ( $12 \%$ vs. a few percent) and the baby bunches were also much larger (8-10\% ${ }^{30}$ vs $\left.2-3 \%\right)$. Unfortunately, there were not detailed measurements of $\varepsilon$ along the ramp in run 12. In particular, a measurement after the loss right at the beginning of the ramp would've been relevant. The flattop $\varepsilon$ in run 12 was about the same as the $\varepsilon$ measured just after the merge, but before the ramp $(0.56 \mathrm{eVs} / \mathrm{n}) .{ }^{31}$ As noted earlier, this run $\varepsilon$ just after the merge was $0.43 \mathrm{eVs} / \mathrm{n}$.

\footnotetext{
${ }^{29}$ Jun 1920121457 Booster-AGS elog entry

30 Jun 1920121445 Booster-AGS elog entry

31 Jun 1920121530 Booster-AGS elog entry
} 
In summary, the AGS injected, post merge, and before bank transfer $\varepsilon$ is about $0.40 \mathrm{eVs} / \mathrm{h}$, the late ramp and flattop $\varepsilon$ is about $0.65 \mathrm{eVs} / \mathrm{n}$. There appears to be about a factor of about 1.6 increase in $\varepsilon$ from the bank transfer to flattop, and most, if not all of that seems to happen before transition.

\section{EBIS Emittance}

So far, it seems that a merged bunch coming out of the Booster is about $0.089 \mathrm{eVs} / \mathrm{n}$, and an unmerged batch of 4 Booster bunches is about $0.08 \mathrm{eVs} / \mathrm{n}$. So there's not much contribution to emittance from the Booster merge, but how those emittances compare to the emittance of the EBIS beam is yet to be shown. In this section, a debunching measurement at Booster injection is described.

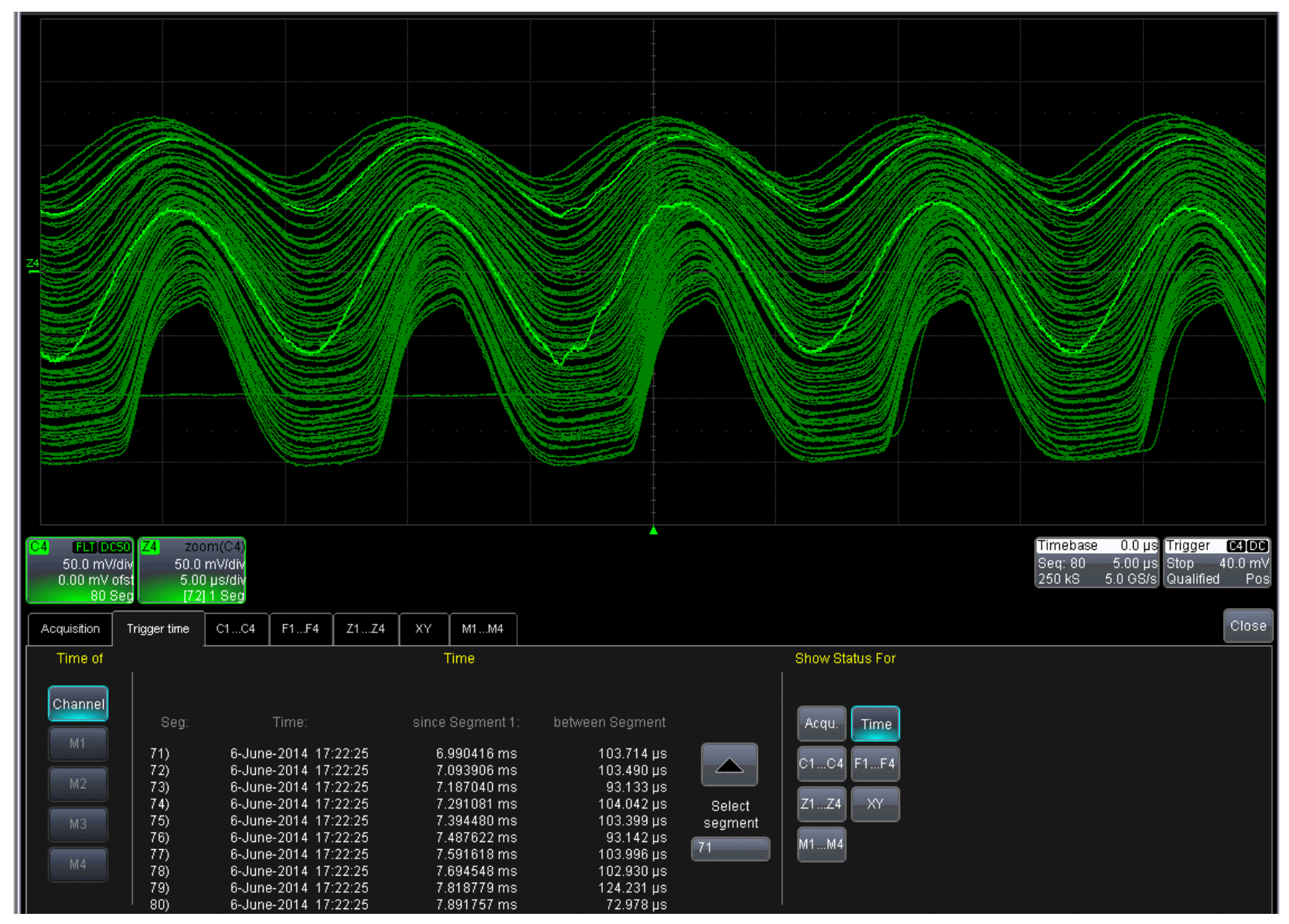

Figure 20: Mountain range display of debunching beam at Booster injection using a narrow pulse from EBIS. The D1 PUE sum is used here instead of the WCM because it has a stronger signal.

Figure 20 shows the mountain range used to find $d p / p$. The sum of the 2 plates of the D1 pickup electrodes (D1 PUE) are used instead of the WCM because they provide a less noisy signal. The frequency response of this signal suffers from the same problem that the WCM signal does, but with pulses this wide it is considered adequate for the job. This measurement is more difficult than the one in the AGS because the edges of the pulse, particularly the trailing one are not as sharp. As in figure 15, the trace at which the two edges appear to meet is highlighted. The highlighted trace (\#72) is then displayed 
below it again with a higher gain. ${ }^{32}$ From the readout at the bottom of figure 20 trace 72 occurs $7.1 \mathrm{~ms}$ after the first trace of the display, which is right at injection, so $t_{d b}$ is $7.1 \mathrm{~ms}$.

Since the trailing edge does not have a sharp edge it's hard to measure the pulse width accurately; a value of $7.3 \mu \mathrm{s}$ is used. ${ }^{33}$ The revolution period is $10.35 \mu \mathrm{s}$, so a $7.3 \mu$ s full width corresponds to a half width of $7.3 \pi / 10.35=2.21$ radians, $\eta$ is -0.954 . Solving for $d p / p$ in the debunching equation gives $d p / p=0.22 \mathrm{e}-3$. To estimate the $\varepsilon$ of the injected beam, the energy spread around the ring is approximated as constant so that $\varepsilon$ will be equal to $2 \Delta \mathrm{E} \tau / \mathrm{A}$, where $\Delta \mathrm{E}$ is the half width of the energy spread, $\tau$ is the revolution period, and $A$ is the number of nucleons in an $A u$ atom (197). From Bbat, as described in figure 21 , a dp/p of $0.22 \mathrm{e}-3$ corresponds to a $\Delta \mathrm{E}$ of $0.17 \mathrm{MeV}$. So $\varepsilon$ is then equal to $(2 * 0.17$ $\left.\mathrm{MeV}^{*} 10.35 \mu \mathrm{s}\right) / 197=0.018 \mathrm{eVs} / \mathrm{n}$. A difference in $\mathrm{t}_{\mathrm{db}}$ of $1 \mathrm{~ms}$ either way corresponds to a difference in $\varepsilon$ of about $0.003 \mathrm{eVs} / \mathrm{n}$. A variation in the pulse width of $10 \%$ causes $\varepsilon$ to vary by about $0.005 \mathrm{eVs} / \mathrm{n}$. Combining the effects of these 2 possible error sources gives $\varepsilon=0.018 \pm 0.008 \mathrm{eVs} / \mathrm{h}$, which is about a quarter of the emittance measured at Booster extraction $(0.08 \mathrm{eVs} / \mathrm{n}$ for the unmerged case).

\section{Booster Capture Measurements}

Although there are strong limitations on where in the cycle the WCM gives valid bunch width data, as noted earlier, there's reason to believe that its frequency response is adequate very early in the cycle where the bunches are wide. Since this part of the cycle is where RF capture occurs, it is of interest as a potential source of emittance growth, and measurements were taken there.

A series of those measurements were taken, mostly on June 26 , table III shows the results. ${ }^{34}$ Figure 22 illustrates how the bunch width measurements were made using the 14.5 and 18.5 ms cases (injection occurs at Bt0+10.5 ms). It would be helpful to be to get some data from before $14.5 \mathrm{~ms}$, but the earlier the measurements are the harder it is to find the edge of the bunch. For times earlier than $14.5 \mathrm{~ms}$, it's hard to get any confidence in the measurement. On the other hand, the latter measurements have relatively well defined bunches.

\footnotetext{
32 Jun 620141726 Booster-AGS elog entry

33 Jun 620141731 Booster-AGS elog entry

34 Injection $+4,6$, and 8 ms on June $261234-1359$ B-A elog entries, Injection +5 ms on July 22014,1712 B-A elog entry, Injection $+9.5 \mathrm{~ms}$ on July 12014,1828 and 1833 B-A elog entries
} 


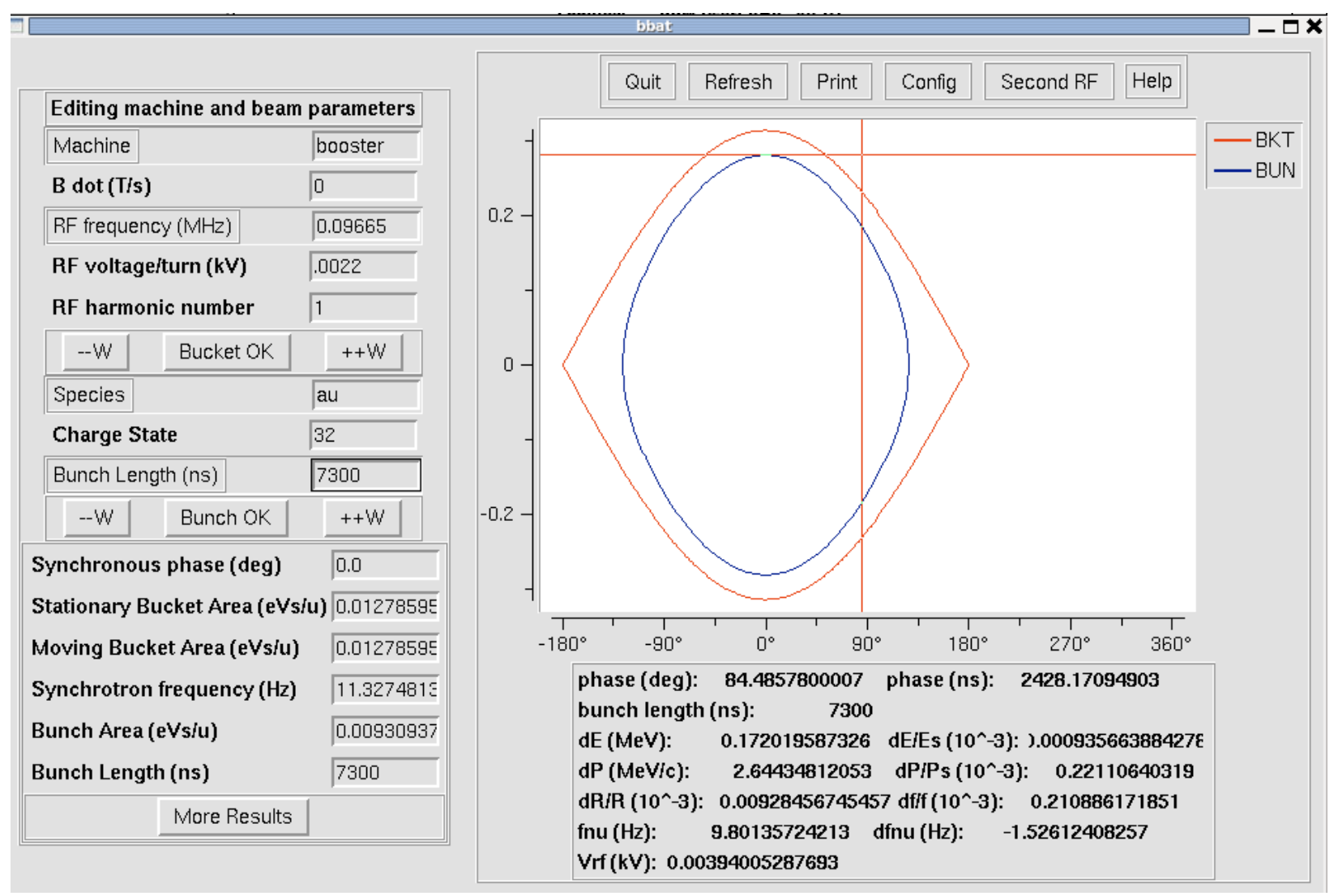

Figure 21: Finding $\Delta E$ from $\mathrm{dp} / \mathrm{p}$ using Bbat. By setting the RF frequency to the revolution frequency $0.09665 \mathrm{MHz}(\mathrm{h}=1)$ and the particle type appropriately one can find $\Delta \mathrm{E}$ from the parameters below the plot in the Bbat window. The horizontal red line is adjusted to get $d p / p=0.22 e-3$ which can be seen is equivalent to a $\Delta E$ of $0.17 \mathrm{MeV}$.

\begin{tabular}{|l|l|l|l|l|l|l|}
\hline Time $(\mathrm{ms})$ & $\begin{array}{l}\mathbf{d B} / \mathbf{d t} \\
(\mathrm{g} / \mathrm{ms})\end{array}$ & $\mathbf{0 . 8} * \mathbf{V}_{\text {ref }}(\mathrm{kV})$ & $\mathbf{V}_{\text {synch }}(\mathrm{kV})$ & $\begin{array}{l}\text { Bunch width } \\
(\mathrm{ns})\end{array}$ & $\boldsymbol{\varepsilon}_{\text {ref }}(\mathrm{eVs} / \mathrm{n})$ & $\begin{array}{l}\boldsymbol{\varepsilon}_{\text {synch }} \\
(\mathrm{eVs} / \mathrm{n})\end{array}$ \\
\hline Inj+4 (14.5) ms & 0 & 0.244 & - & 2383 & 0.065 & - \\
\hline $\operatorname{Inj}+5(15.5) \mathrm{ms}$ & 0 & 0.516 & - & 1427 & 0.049 & - \\
\hline $\operatorname{Inj}+6(16.5) \mathrm{ms}$ & 0 & 1.268 & - & 1478 & 0.081 & - \\
\hline $\operatorname{Inj}+8(18.5) \mathrm{ms}$ & 0 & 5.73 & - & 924 & 0.075 & - \\
\hline $\operatorname{Inj}+8(18.5) \mathrm{ms}$ & 0 & 5.73 & - & 970 & 0.083 & - \\
\hline $\operatorname{Inj}+9.5(20.0) \mathrm{ms}^{* *}$ & 7 & 9.35 & 9.98 & 783 & 0.072 & 0.074 \\
\hline
\end{tabular}

Table III: Emittance measurements along the injection/capture porch taken on June 26 except where noted. The RF voltage was estimated from the calibration found at extraction $(25.2 / 31.5=0.80)$. The $\varepsilon$ values are the per bunch value multiplied by 4 (because there are 4 bunches). ${ }^{*}$ indicates taken on July $2, * *$ indicates taken on July 1 . Parameters are as shown in Table I. 


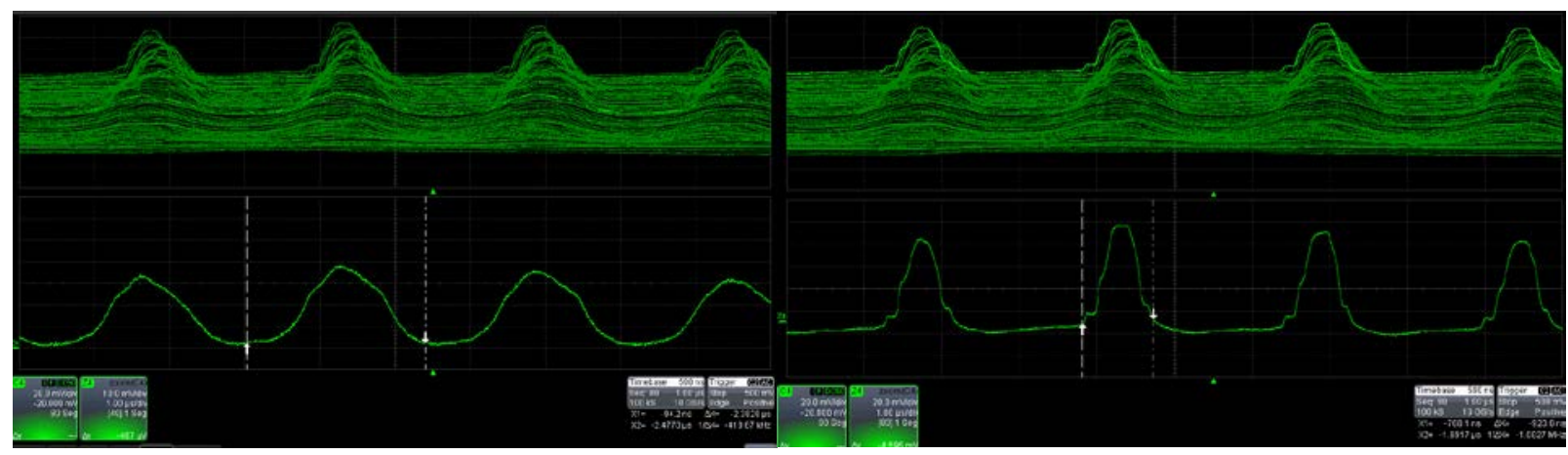

Figure 22: Bunch width measurements for $14.5 \mathrm{~ms}$ (left) and $18.5 \mathrm{~ms}$ (right) cases. Also shown is the first $8 \mathrm{~ms}$ on the mountain range display. The trace for each case is highlighted in the respective mountain range displays and shown beneath each.

In general, the RF voltage was estimated from the calibration found at Booster extraction $0.80 * V_{\text {ref, }}$, here $V_{\text {ref }}$ is the sum of the references for the 2 cavities, $A 3$ and $B 3 .{ }^{35}$ The nominal RF voltage function is shown in figure 23 . In the injection+ $9.5 \mathrm{~ms}$ case the synchrotron frequency was also measured. ${ }^{36}$ It gave a voltage $6.7 \%$ higher than the estimated voltage. If that calibration is used for the rest of the data it makes the emittance about $2.5-5 \%$ higher than indicated in the table for $\varepsilon_{\text {ref. }}$.

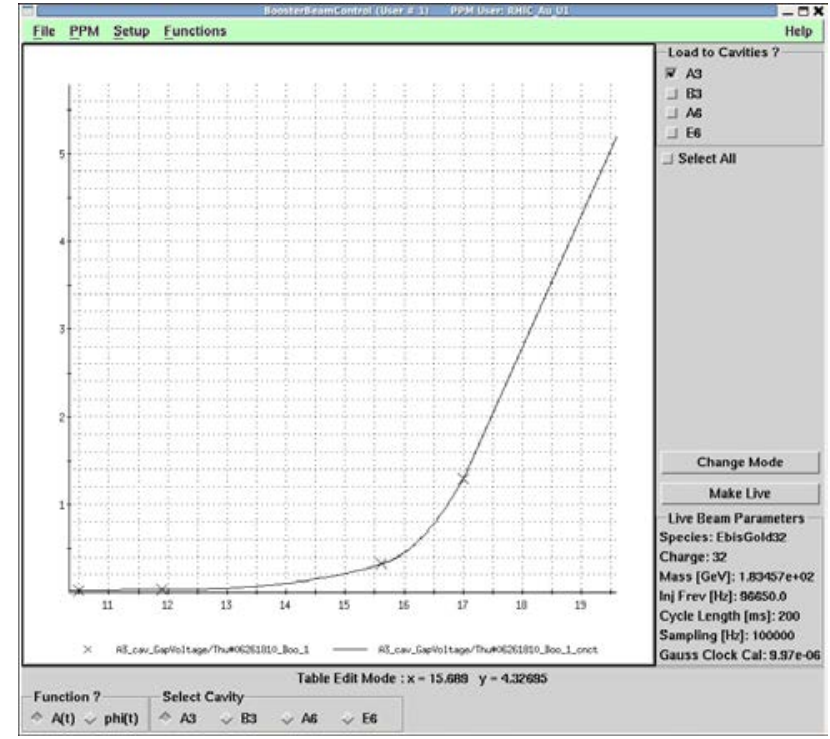

Figure 23: RF voltage reference function used for the measurements in Table III. This was also the nominal function used for running at that time. The estimated voltage used for emittance calculations is 0.80 times twice the voltage shown here (there are 2 cavities). $X$-axis is time from Bt0 in milliseconds, $y$-axis is kilovolts. The section from 10.5 to 15.6 ms is cubic, from 15.6 to $17 \mathrm{~ms}$ it's quadratic, and from $17 \mathrm{~ms}$ on it is linear.

The values for $\varepsilon$ during the latter part of capture are close to that found for $\varepsilon$ at Booster extraction, about $0.08 \mathrm{eVs} / \mathrm{n}$. The values earlier are perhaps somewhat lower, $0.065 \mathrm{eVs} / \mathrm{n}$ at $14.5 \mathrm{~ms}$,

\footnotetext{
${ }^{35}$ It's curious that the calibrations arrived at for the Booster (at extraction) and AGS (at flattop) voltage from the measured synchrotron frequencies are essentially the same, $0.80 \mathrm{vs.} 0.795$, respectively.

${ }^{36}$ July 120141833 B-A elog entry
} 
and $0.049 \mathrm{eVs} / \mathrm{n}$ at $15.5 \mathrm{~ms}$. These measurements also assume an equilibrium condition, which clearly is not the case if there is emittance growth. But it seems reasonable to wonder whether, since the values late in the process are close to that measured at extraction, and the value from the debunching measurement right at injection $(0.018 \mathrm{eVs} / \mathrm{n})$ is smaller, that emittance growth might be occurring during the capture process. As can be seen in figure 22, the $18.5 \mathrm{~ms}$ bunch has tails which are also a sign of emittance growth. There are also tails in the 16.5 and $20 \mathrm{~ms}$ cases. At $20 \mathrm{~ms}$ the magnet has begun to ramp, $\mathrm{dB} / \mathrm{dt}$ is $7 \mathrm{~g} / \mathrm{ms}$ there.

In order for this data to be meaningful the cavities need to regulate well at these very low voltages. The readbacks of the cavity voltages indicate that they do. The response of the beam to changes in the voltage functions also seem to indicate that the cavities are regulating properly. This kind of analysis would've been a lot more difficult before this run because the cavities did not regulate well enough with the previous LLRF system and counterphasing was required.

To further investigate the apparent emittance growth, the length of the capture porch was doubled, and the RF voltage was adjusted to rise more slowly. ${ }^{37}$ Little time was spent trying to flatten this porch, but the beam survival to the end of it was reasonable. It was found that capture, judging from the mountain range display, was poor unless RF track, which starts the sweeping of the RF frequency, was not enabled. It typically comes on around the middle of the capture porch. The AC phase loop, which normally comes on early in the standard porch, was not adjusted for this test. The beam did not accelerate in this state (nor was it expected to).

A constant voltage reference of $0.03 \mathrm{kV}$ (corresponding to an estimated voltage of $0.048 \mathrm{kV}$ ) from $10.5 \mathrm{~ms}$ (injection) to $12.0 \mathrm{~ms}$, followed by a quadratic reference from $12 \mathrm{~ms}$ to $25.7 \mathrm{~ms}$ (the end of the extended porch) was used (like the one in figure 24). The voltage at $25.7 \mathrm{~ms}$ was adjusted to vary the final voltage of the quadratic segment. The emittance was calculated for different final voltages from the bunch widths measured at $25.7 \mathrm{~ms}$.

Table IV shows the results. They indicate that the measured $\varepsilon$ increases as the voltage at 25.7 $\mathrm{ms}$ is increased. This isn't a surprise, but perhaps what is one is how little the voltage needs to be raised before the measured $\varepsilon$ increases. In the normal running case, the voltage is raised to $5.7 \mathrm{kV}$ in the first 8 $\mathrm{ms}$, these measurements suggest that raising it to only a tenth of that over twice as long increases the emittance significantly (from 0.035 to $0.048 \mathrm{eVs} / \mathrm{n}$ ). Figure 25 shows the measurement for the lowest voltage at $25.7 \mathrm{~ms}\left(\mathrm{~V}_{\text {ref }}=0.413 \mathrm{kV}\right)$. Even at this low voltage the bunches are clearly separated, although it's still quite difficult to distinguish tails from extraneous noise.

37 July 32014 B-A elog $1252-1333$ entries 


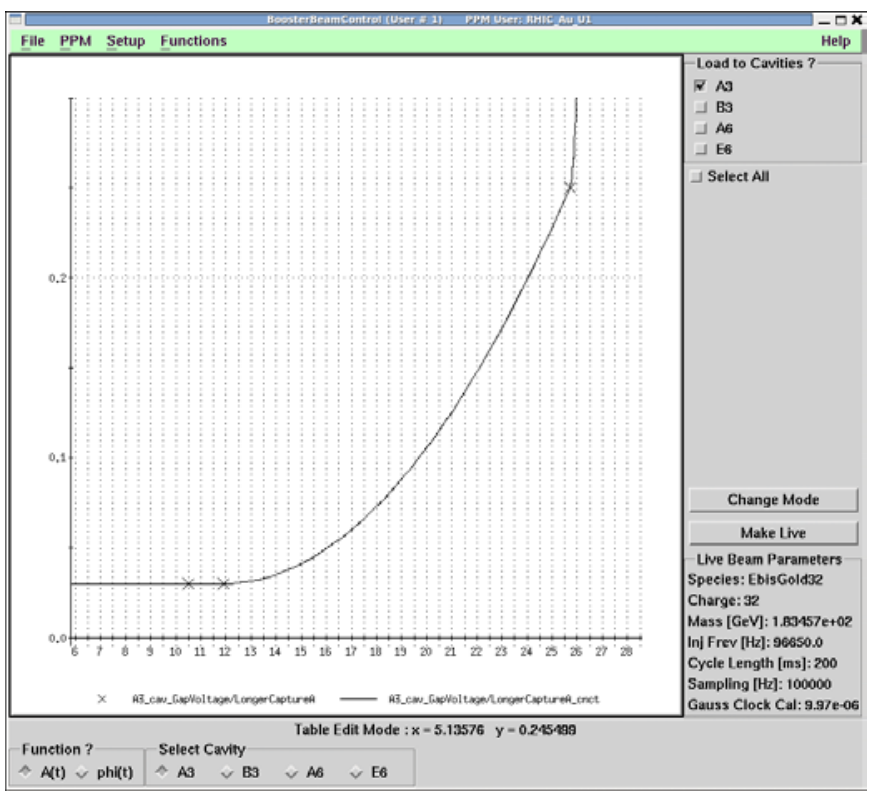

Figure 24: The voltage function that was used to scan the rate of rise of the voltage during the capture porch. The voltage of the point at $\mathbf{2 5 . 7} \mathrm{ms}$ was adjusted to adjust the slope of the quadratic segment.

\begin{tabular}{|l|l|l|}
\hline $\mathbf{0 . 8} * \mathrm{~V}_{\text {ref }}(\mathrm{kV})$ & Bunch width (ns) & $\boldsymbol{\varepsilon}_{\text {ref }}(\mathrm{eVs} / \mathrm{n})$ \\
\hline 0.413 & 1222 & 0.034 \\
\hline 0.537 & 1372 & 0.047 \\
\hline 1.073 & 1130 & 0.047 \\
\hline 1.608 & 1056 & 0.051 \\
\hline 2.147 & 1045 & 0.058 \\
\hline
\end{tabular}

Table IV: Emittance data for extended capture porch and different final voltages.

Since the beam was not accelerated, it can't be proven that the entire beam has been captured here, but it appears that by raising the voltage slowly enough it may be possible to keep $\varepsilon$ as small as $0.034 \mathrm{eVs} / \mathrm{n}$. This is closer to the value measured from $\mathrm{dp} / \mathrm{p}(0.018 \pm 0.008 \mathrm{eVs} / \mathrm{n})$ for the incoming emittance, though still almost twice as lagre. It could be argued that this is a method for gauging the incoming emittance as well (or at least finding an upper bound), since there doesn't seem to be much in the way of tails developing at the lowest voltage. Given that the debunching measurement is difficult, some disagreement isn't surprising. It would have been helpful here if I had also looked at voltages higher than $2.1 \mathrm{kV}$, though the trend is pretty clear. 


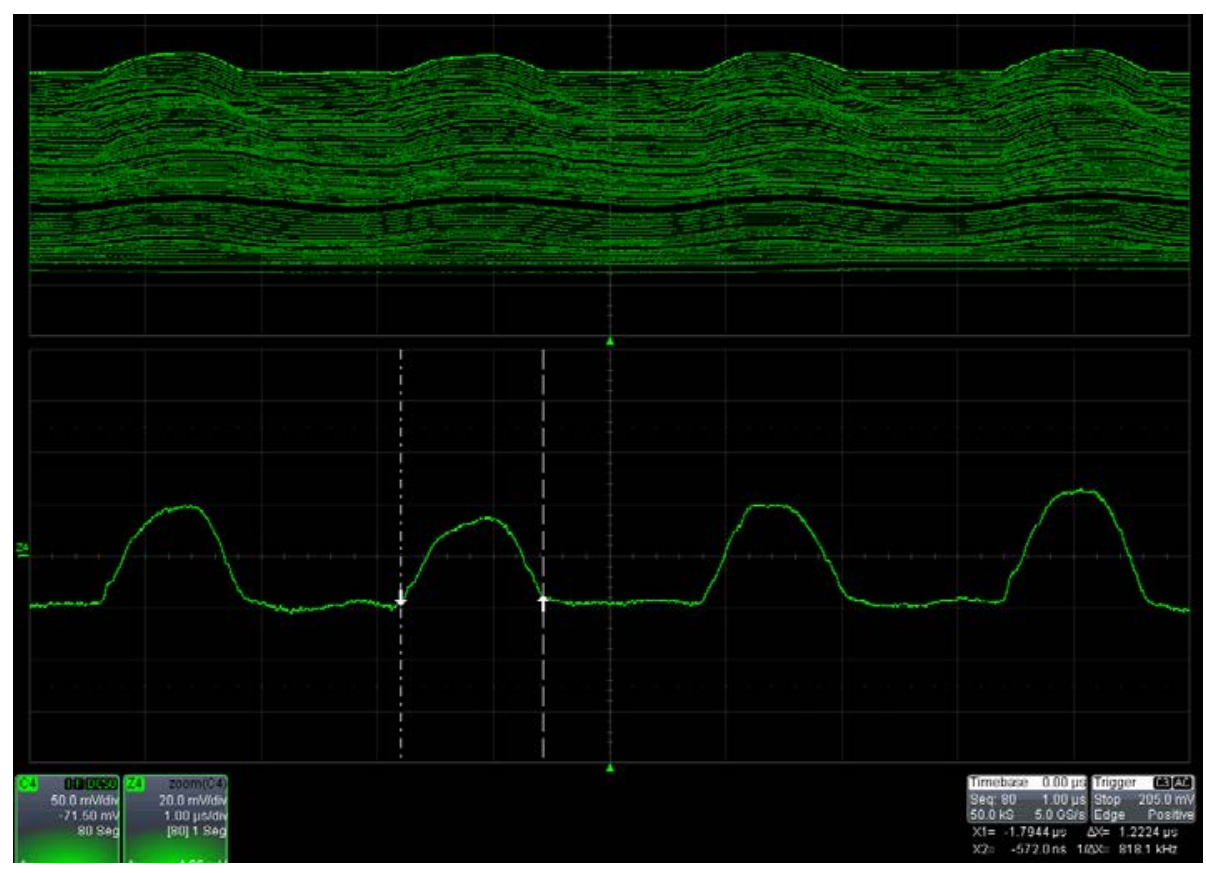

Figure 25: WCM Bunch width measurement for a voltage of $0.413 \mathrm{kV}$ at $25.7 \mathrm{~ms}$ on an extended porch.

Doubling the voltage from 0.048 to $0.096 \mathrm{kV}$ on the constant segment made the capture look much worse, implying that the initial matching voltage is not unreasonable. If one assumes that $0.048 \mathrm{kV}$ is the matching voltage, then the incoming emittance can be calculated using a bunch width that's one quarter of the revolution period wide ( $2580 \mathrm{us}$ ). That would give an emittance of $0.0075 \mathrm{eVs} / \mathrm{n}$ for one bunch, or $0.030 \mathrm{eVs} / \mathrm{n}$ for 4 bunches (the nominal injection voltage is $0.033 \mathrm{kV}$ which gives $0.025 \mathrm{eVs} / \mathrm{n}$ ).

The emittance that's measured at the end of nominal capture looks to be several times larger than it is at injection, and it's close to what's measured late in the cycle. So, at least there doesn't seem to be much growth through the rest of the cycle. It looks like this emittance growth during capture could be reduced by a factor of 2 (or more) if much more time is left in the cycle for it, but there is nowhere near the required amount of time available for that in the present setup.

\section{Summary}

Table $V$ attempts to summarize all the emittance measurements discussed above. Although there's a fair amount of uncertainty in a lot of these measurements, it looks like there are 2 main times where significant emittance growth occurs; at Booster RF capture, and during AGS acceleration after the transfer from the flattop bank to the pulsed bank for the AGS main magnet.

The growth associated during capture appears to be the largest. Although, mainly due to the uncertainty in the incoming emittance, there is a lot of uncertainty in how much growth there actually is. Some measurements taken with an extended capture porch suggest that taking more time to capture would help to reduce this growth, but there is little time for that available in the present setup. The growth after the bank transfer looks like about a factor of 1.6. Although it's far from certain, the most 
likely source of that growth seems to be associated with oscillations in the beam radius and/or phase associated with the RF trying to cope with the oscillations in the main magnet field when on the pulsed bank.

\begin{tabular}{|l|l|l|l|l|l|}
\hline $\mathbf{t}$ & Part of the cycle & $\begin{array}{l}\text { Total Booster } \\
\text { Emittance }(\mathbf{e V} \mathbf{s} / \mathbf{n})\end{array}$ & $\begin{array}{l}\text { Per AGS bunch } \\
\text { emittance }(\mathbf{e V} \mathbf{s} / \mathbf{n})\end{array}$ & \multicolumn{2}{|l|}{ Emittance growth } \\
\cline { 5 - 6 } & & $0.018-0.03$ & $0.072-0.12$ & $\mathbf{t}_{\mathbf{a}}->\mathbf{t}_{\mathbf{b}}$ & Ratio \\
\hline 1 & Booster Injection & $0.074-0.083$ & $0.30-0.33$ & - & - \\
\hline 2 & Booster just after capture & 0.080 & 0.32 & $1->2$ & $2.5-4.6$ \\
\hline 3 & Booster without merge & 0.36 & $2->3$ & $0.96-1.08$ \\
\hline 4 & Booster extraction (before foil) & 0.089 & $0.35-0.45$ & $4->4$ & 1.11 \\
\hline 5 & AGS injection (after foil) & $0.09-0.10$ & $->5$ & $0.99-1.29$ \\
\hline 6 & AGS after merge & - & 0.43 & $5->6$ & $0.96-1.22$ \\
\hline 7 & AGS before bank transfer & - & $0.40-0.43$ & $6->7$ & $0.93-1.00$ \\
\hline 8 & AGS just before transition & - & 0.62 & $7->8$ & $1.44-1.55$ \\
\hline 9 & AGS Flattop & - & $0.63-0.75$ & $8->9$ & $1.01-1.21$ \\
\hline- & Booster injection to extraction & - & - & $1->4$ & $3-4.9$ \\
\hline- & Booster extraction to AGS flattop & - & - & $4->9$ & $1.77-2.11$ \\
\hline- & AGS injection to flattop & - & - & $5->9$ & $1.40-2.14$ \\
\hline- & Booster injection to AGS flattop & - & - & $1->9$ & $5.25-10.4$ \\
\hline
\end{tabular}

Table V: Summary of Emittances through the Booster and AGS cycles. "Total Booster emittance" is the sum of the emittances of all the bunches at a particular time in the cycle. "Per AGS bunch emittance" is the total emittance of the beam if it were in one final AGS bunch, or the beam in 1 final AGS bunch, as the case may be. The ranges given are just the ranges in the different measurements taken (any values without ranges are from just one measurement). The emittance growth ratio is the ratio of emittance at $t_{b}$ over that at $t_{a}$ ( $t$ in the leftmost column) of the "Per AGS bunch" emittance.

Short of changing the entire setup, it's not clear what can be done to improve Booster capture. It's also the case that if the growth during capture were less that the growth associated with the Booster merge and the BtA foil would become more of an issue.

In the case of the merge, the smaller the incoming beam, the more the effect any growth during the merge would have on the emittance. For instance, if the difference between $\varepsilon$ for Booster extraction with and without the merge is to be believed, the effect of the merge can be quantified as,

$$
\varepsilon_{\text {total }}=\sqrt{\varepsilon_{0}^{2}+\Delta \varepsilon_{\text {merge }}^{2}}
$$

where $\varepsilon_{\text {total }}$ is $\varepsilon$ after the merge (at Booster extraction) and has contributions from $\varepsilon$ coming into the merge $\left(\varepsilon_{0}\right)$ and from the merge $\left(\Delta \varepsilon_{\text {merge }}\right)$. In the case where $\varepsilon_{\text {total }}=0.089 \mathrm{eVs} / \mathrm{h}$ and $\varepsilon_{0}=0.080 \mathrm{eVs} / \mathrm{n}$, that would make $\Delta \varepsilon_{\text {merge }}=0.039 \mathrm{eVs} / \mathrm{n}$. So, if say $\varepsilon_{0}$ were 0.040 instead of $0.080 \mathrm{eVs} / \mathrm{n}, \varepsilon_{\text {total }}$ would be $\sqrt{0.040^{2}+0.039^{2}}$ or $0.056 \mathrm{eVs} / \mathrm{n}$, not $(0.089 / 0.08)^{*} 0.04 \mathrm{eVs} / \mathrm{n}=0.044 \mathrm{eVs} / \mathrm{n}$. So, instead of a $10 \%$ effect it would be a $40 \%$ effect. Similarly, the relative effect of the foil would increase since the $\mathrm{dp} / \mathrm{p}$ imparted by it would stay constant as the extracted $\mathrm{dp} / \mathrm{p}$ got smaller. As far as the growth from the AGS merge goes, there is plenty of time to accomplish it, so it probably wouldn't be much of an issue. 
As for the growth during the AGS ramp, if it's due to the main magnet voltage ripple, it looks like using the $A C$ phase loop and the lower voltage tap simultaneously would have the best chance of reducing it but it doesn't seem likely that would completely solve the problem.

Through all this the question of how a smaller emittance would benefit RHIC hasn't been directly addressed. RHIC seems to run reasonably well with the present emittance, the main interest seems to be for more intensity. If the EBIS current doesn't increase, the only obvious way to get more bunch intensity is to put more Booster transfers into one bunch. But the more Booster loads are merged into one bunch, the bigger the merged bunch will become, the less beam will fit into the main $\mathrm{h}=12$ buckets. Though not well understood, it also seems likely that the loss right at the beginning of the ramp, associated with the squeeze, will get worse. The loss at the bank transfer will also likely get worse, since it seems related to how full the buckets are there. So, the way to alleviate these problems is to make the bunches injected into the AGS smaller.

It would be possible to do a 12 to 6 to 2 AGS merge; the merge that was employed during Tandem running, except with 2 final AGS bunches instead of 4 . However, there are drawbacks and limitations related to that which have nothing to do with emittance. One drawback is the AGS cycle length that would be required. The AGS cycle length required to provide 2 AGS bunches of 6 transfers each would be about $7.2 \mathrm{sec}$, instead of the $5.2 \mathrm{sec}$ length used this run. ${ }^{38}$ Since each Booster cycle is $200 \mathrm{~ms}$, you might think the increase in cycle length would be only $800 \mathrm{~ms}$ instead of 2 seconds. The difference is due to the line voltage (PPMR) constraint on the Booster main magnet that needs to be satisfied.

Even if the line voltage requirement were satisfied, the EBIS needs to be able to provide 12 pulses per AGS cycle. During this run, the 8 pulses delivered per AGS cycle were the maximum EBIS personnel were comfortable with delivering. Also, the Booster emittance would likely be about the same, so due to the problems mentioned above, how much, if any, the final AGS per bunch intensity would increase is far from clear.

It would be possible to deliver only one bunch composed of 6 Booster loads per AGS cycle within both the EBIS pulsing and Booster power line constraints, and perhaps with a longer capture porch in Booster, but the RHIC fill time would be nearly doubled. Aside from just the increase in filling time, that would be problematic due to emittance growth during RHIC injection associated with Intra-beam scattering. How much of a benefit a longer capture porch would be is also not known, but if it did reduce the emittance growth there, it would alleviate the problems associated with fitting 6 Booster transfers into 1 AGS bunch. ${ }^{39}$ On the other hand, the emittance growth observed after the bank transfer probably doesn't adversely affect the bunch intensity delivered to RHIC.

\footnotetext{
${ }^{38}$ That setup requires 2 different Booster users with slightly different merge porch energies to satisfy the PPMR constraints, but seems possible aside from the EBIS constraints. Feb 152014 Booster-AGS elog entry
} 